\title{
Review Article \\ Intrathecal IgG Synthesis: A Resistant and Valuable Target for Future Multiple Sclerosis Treatments
}

\author{
Mickael Bonnan \\ Service de Neurologie, Hôpital F. Mitterrand, 4 boulevard Hauterive, 64046 Pau, France \\ Correspondence should be addressed to Mickael Bonnan; mickael_bonnan@yahoo.fr
}

Received 28 September 2014; Revised 15 December 2014; Accepted 16 December 2014

Academic Editor: Bianca Weinstock-Guttman

Copyright (C) 2015 Mickael Bonnan. This is an open access article distributed under the Creative Commons Attribution License, which permits unrestricted use, distribution, and reproduction in any medium, provided the original work is properly cited.

\begin{abstract}
Intrathecal IgG synthesis is a key biological feature of multiple sclerosis (MS). When acquired early, it persists over time. A growing body of evidence suggests that intrathecal Ig-secreting cells may be pathogenic either by a direct action of toxic IgG or by locally secreting bystander toxic products. Intrathecal IgG synthesis depends on the presence of CNS lymphoid organs, which are strongly linked at anatomical level to cortical subpial lesions and at clinical level to the impairment slope in progressive MS. As a consequence, targeting CNS lymphoid lesions could be a valuable new target in MS, especially during the progressive phase. As intrathecal IgGs are end-products of these lymphoid lesions, intrathecal IgG synthesis may be considered as a specific marker of the persistence of these inflammatory lesions. Here we review the effect upon intrathecal IgG synthesis of all drugs ever used in MS. Except for steroids, all these therapeutic strategies, including rituximab, failed to decrease intrathecal IgG synthesis, with the exception of a questionable incomplete action of natalizumab. Thus, IgG synthesis is a robust marker of persistent intrathecal inflammation and its complete normalization should be one of the goals in future therapeutic strategies.
\end{abstract}

\section{Introduction}

Intrathecal IgG synthesis is a key biological feature of multiple sclerosis (MS). A growing body of evidence suggests that intrathecal IgG secreting cells may be pathogenic either by a direct action of toxic IgG or by locally secreting bystander toxic products of B-cells (review in [1]).

We first provide a brief introduction to the synthesis pathway of intrathecal IgG in the context of CNS lymphoid organs. As intrathecal IgGs are end-products of these lymphoid infiltrates, intrathecal IgG synthesis may be considered as a specific marker of the persistence of these inflammatory lesions. Here we review the consequences on intrathecal IgG synthesis of all drugs given in the past in MS. We make special mention of rituximab and natalizumab owing to their paradoxical action on intrathecal IgG synthesis.

\section{Pathway of Intrathecal IgG Synthesis}

Multiple sclerosis (MS) is characterized by intrathecal $\operatorname{IgG}$ synthesis that occurs as a very early event and is the most robust diagnostic biological criterion of the disease. Either an elevated IgG index or oligoclonal bands (OCB) are found positive in more than $95 \%$ MS patients $[2,3]$. In the few patients $(<0-5 \%)$ lacking intrathecal synthesis, a repeated cerebrospinal fluid (CSF) exam is often positive [4-7] and intrathecal secretion is demonstrated by many other techniques such as MRZ reaction, high CSF IgA synthesis [8, 9], oligoclonal free $\kappa$ light-chains [10], or clonal $V_{H}$ and CDR rearrangements $[11,12]$, suggesting that OCB and IgG index tests are insufficiently sensitive. Once acquired, intrathecal synthesis persists mostly unchanged over time [13-17] and never disappears. Moreover, the intimate affinity maturation of IgG and the peptidic targets of OCB IgG persist over time $[2,18,19]$. As a consequence, each patient has a unique pattern "OCB fingerprint" of CSF immunoglobulins [20, 21]. This biological signature may be scored according to the typical positions of mutational replacements (hotspots) on $\operatorname{IgG}$ and can be used as a composite signature $Z$-score, which is highly predictive of the conversion of clinically isolated syndromes (CIS) to clinically defined MS [22, 23]. These hotspot codons reside in the complementary determining 
region (CDR) where they are predicted to have contact with the (unknown) antigen(s).

A growing set of evidences points to a central role of compartmentalized lymphoid tissue (tertiary lymphoid organs, TLO) in the formation and maintenance of intrathecal IgG synthesis $([24,25]$, review in $[26-28])$. The main somatic hypermutations found in IgG are to be found in the CDR [12], which is targeted by the enzyme activation-induced cytidine deaminase (AICD) that is specifically expressed by $\mathrm{B}$-cells in the context of lymphoid organs. The complex process of $\operatorname{IgG}$ affinity maturation also requires dendritic cells as professional antigen-presenting cells; cognate maturation of B-cells in collaboration with T-cells; clonal proliferation and selection in local germinal centers, provided by the TLO structure. Moreover, indirect evidence of intrathecal lymphoid structures is provided by deep analysis of the clonal lineage of IgG and B-cells inside and outside the CNS. CSF IgG, plasmablasts, and plasma cells are expanded from a few single ancestors and are clonally related. Although present on both sides of the blood-brain-barrier (BBB), clonal Bcell and T-cell lineages are mostly confined to the CNS, sometimes "private" to brain regions, indicating a mainly local continuous affinity maturation inside the CNS [29-33]. In animal models, the TLO correlates with epitope spreading in T-cells [34].

Furthermore, both intrathecally synthesized IgG and the underlying lymphoid organs are potentially involved in the pathophysiology of cortical lesions (review in $[1,35]$ ). Although no specific target has yet emerged, converging evidence indicates that IgG may directly target CNS structures [36-40]. Inflammatory cells may also be toxic owing to IgG-independent mechanisms [41-44]-TNF $\alpha$, lymphotoxin, and IFN $\gamma$ being good candidates [45] and B-cells their potential source [46]. Finally, the meningeal lymphoid tissue observed in MS patients is spatially correlated to type III cortical lesions $[25,47,48]$. These cortical lesions represent half of the cortical lesions, cover up to $40-60 \%$ of the cortical ribbon in progressive MS, and are associated with a major neuronal loss [49-51]. Lastly, both cortical lesions and TLO strongly correlate with clinical impairment $[25,35,47,52]$.

In conclusion, intrathecal synthesis is an early-occurring event in the course of MS, which, once acquired, persists essentially unchanged throughout life and may be involved in the pathogenesis of progressive MS. Since cortical subpial lesions, TLO, intrathecal IgG synthesis, and impairment are intimately linked, it might be valuable to target B-cells situated in the TLO and to evaluate the effect in terms of their final product, that is, intrathecal IgG synthesis.

\section{Technical Limitations in CSF IgG Measurement Leading to Underestimation of Ig Synthesis}

Techniques and norms have been developed in order to help clinicians for the diagnosis of MS [53]. For example, unique CSF BOC are discarded due to low specificity and the cutoff for CSF IgG is high [54]. We propose here shifting from the usual point of view to examining techniques used to demonstrate intrathecal synthesis as low as appears in known MS patients.

CSF is actively secreted by choroid plexus and drains into the venous flow. Blood proteins passively enter the CSF through natural leakages of BBB. Albumin is not secreted in the CSF and comes exclusively from blood. A direct measurement of the IgG synthesis rate would be useful but unfortunately the existing formulae provide limited information.

The de novo CNS IgG synthesis rate (Tourtellotte's formula) is calculated as

$$
\begin{aligned}
\mathrm{IgG}_{\mathrm{SYN}}=[( & \left.\mathrm{IgG}_{\mathrm{CSF}}-\frac{\mathrm{IgG}_{\text {serum }}}{369}\right)-\left(\mathrm{Alb}_{\mathrm{CSF}}-\frac{\mathrm{Alb}_{\text {serum }}}{230}\right) \\
& \left.\times\left(\frac{\mathrm{IgG}_{\text {serum }}}{\mathrm{Alb}_{\text {serum }}} 0.43\right)\right] \times 5,
\end{aligned}
$$

based on isotope studies in MS patients [55]. Normal values are lower than $3.3 \mathrm{mg} /$ day and the median value in MS patients is $29 \mathrm{mg} /$ day (range 0 to $207 \mathrm{mg} /$ day) [55]. The CSF synthesis rate (5 times a day) is highly variable and the assumption that it is constant is incorrect. Moreover, inconsistent negative results are sometimes obtained so this formula appears unreliable.

The albumin quotient (or ratio), $Q_{\mathrm{Alb}}=\left[\mathrm{Alb}_{\mathrm{CSF}}\right] /$ $\left[\mathrm{Alb}_{\text {serum }}\right]$, is a widely used parameter of BBB dysfunction that increases with its permeability. In the basal state, CSF IgG levels come exclusively from the passive diffusion of blood IgG since the latter are not normally secreted inside the CSF. As a consequence, intrathecally secreted IgG cannot be directly measured and are approximated by calculation using various methods. The IgG quotient, $Q_{\mathrm{IgG}}=\left[\mathrm{IgG}_{\mathrm{CSF}}\right] /\left[\mathrm{IgG}_{\text {serum }}\right]$, denotes this proportionality, as does $Q_{\mathrm{Alb}}$.

The widely used IgG index is a dimensionless formula $\left(Q_{\mathrm{IgG}} / Q_{\mathrm{Alb}}\right)$ expressing the relative excess from expected CSF $\operatorname{IgG}[56,57]$. The normal limit of the $\operatorname{IgG}$ index is below 0.7 , based on the assumption of a linear relation between $Q_{\mathrm{IgG}}$ and $Q_{\mathrm{Alb}}$. However, the work of Reiber et al. largely demonstrated the nonlinearity and age-dependence of this relation [2]. This has two major consequences: (1) a slight fluctuation in IgG or albumin level (either caused by therapeutic or natural fluctuation or by interassay variability) may directly impact the IgG index although intrathecal IgG synthesis remains constant. For example, a $10 \%$ decrease in serum IgG is directly reported as a $10 \%$ increase in IgG index, and day-to-day $10 \%$ variations of IgG index are commonly reported $[58,59]$. (2) The IgG index limit is thought to be constant whereas it is not and depends on many factors (age, $Q_{\mathrm{Alb}}$ ). It would not be a problem if intrathecal IgG synthesis occurred at a high level, but this is unfortunately not the case and the $\operatorname{IgG}$ index is commonly found to be close to the normal limit. As a consequence, minor fluctuations in IgG level may be translated into normal or abnormal IgG index results, although the intrathecal IgG synthesis rate is not really impacted.

The normal upper limit of CSF IgG is better assessed by a hyperbolic discrimination line $\left(Q_{\mathrm{Lim}}=(a / b) \sqrt{Q_{\mathrm{Alb}}^{2}+b^{2}}-c^{2}\right)$, 
where $a, b$, and $c$ are constants, taking into account a wide range of normal population, age, and $\mathrm{BBB}$ permeability [2]. Displaying $Q_{\operatorname{IgG}}$ in a hyperbolic diagram, the Reibergram gives a more exact appreciation of intrathecal IgG synthesis. The fraction of intrathecally synthesized IgG (expressed in \%) is $\operatorname{IgG}_{\mathrm{IF}}=\left[1-Q_{\mathrm{Lim}} / \mathrm{Q}_{\mathrm{IgG}}\right] \times 100$. The median $\operatorname{IgG}_{\mathrm{IF}}$ in $\mathrm{MS}$ is $43 \%$ (max. $86 \%$ ), meaning that $57 \%$ of CSF IgG comes from blood [2]. The intrathecally synthesized IgG concentration (in $\mathrm{mg} / \mathrm{L})$ in CSF is $\operatorname{IgG}_{\mathrm{Loc}}=\left(\mathrm{Q}_{\mathrm{IgG}}-\mathrm{Q}_{\mathrm{Lim}}\right) \times\left[\mathrm{IgG}_{\text {serum }}\right]$, with a median value of $26 \mathrm{mg} / \mathrm{L}$ ( $\max .172 \mathrm{mg} / \mathrm{L}$ ) in $\mathrm{MS}$ [2]. Ig $G_{L o c}$ is the only accurate unbiased calculation available of intrathecally synthesized IgG, giving quantitative results.

The Reibergram was constructed using $Q_{\mathrm{IgG}}$ of $>4000$ control subjects devoid of intrathecal synthesis. The mean normal $Q_{\operatorname{IgG}}$ is noted by $Q_{\text {mean }}$, and $Q_{\text {Lim }}$ - which is $Q_{\text {mean }}+$ $3 \mathrm{SD}$ (standard deviations) for higher specificity-is the higher discriminant line for abnormal $Q_{\mathrm{IgG}}$. $Q_{\mathrm{Low}}\left(Q_{\text {mean }}-\right.$ $3 \mathrm{SD}$ ) is not used. Very low intrathecal synthesis may be displayed below $Q_{\mathrm{Lim}}$. In MS patients, $Q_{\operatorname{IgG}}$ is higher than $Q_{\text {Lim }}$ in about $75 \%$ of cases, which is commonly (and erroneously) interpreted as a null synthesis in the other quarter of patients. However, virtually all MS patients are biased to $Q_{\mathrm{IgG}}>Q_{\text {mean }}$ and none is lower than $Q_{\text {mean }}$, whereas, by definition, $Q_{\operatorname{IgG}}$ with null intrathecal synthesis should be equally distributed (Gaussian) around $Q_{\text {mean }}[2$, 59]. Restraining $Q_{\text {Lim }}$ at $Q_{\text {mean }}+2 \mathrm{SD}$, which includes $96 \%$ of controls, increases positivity of $Q_{\operatorname{IgG}}$ in MS by $10 \%$ [59]. This bias demonstrates that the Reibergram still underestimates intrathecal synthesis and is not sensitive enough to differentiate very low and null intrathecal synthesis. Moreover, the range of $\operatorname{IgG}_{\mathrm{CSF}}$ concentrations between $Q_{\text {Low }}$ and $Q_{\text {Lim }}$ is wide: for common values of $8 \mathrm{~g} / \mathrm{L}$ of $\operatorname{IgG}_{\text {serum }}$ at $Q_{\mathrm{Alb}} 10^{-3}$, the range of IgG $G_{C S F}$ from $Q_{\text {Low }}$ to $Q_{\text {Lim }}$ is about 24 to $64 \mathrm{mg} / \mathrm{L}$, which is substantial.

Consensual examination of oligoclonal bands (OCB) is based on IgG staining after an isoelectric focusing (IF) run, which is more sensitive than electrophoresis [60]. Intrathecal synthesis is defined by the presence of CSF restricted OCB and is usually positive in $>95 \%$ of MS patients [60]. OCB are almost always present when $Q_{\mathrm{IgG}}>Q_{\mathrm{Lim}}$ but are also commonly present when $Q_{\operatorname{IgG}}<Q_{\operatorname{Lim}}[53,60,61]$.

However, isolated monoclonal immunoglobulin bands are sometimes found in CSF. However, owing to their lack of specificity [54], $\geq 2$ OCB are required in most studies to define an oligoclonal pattern with an optimal specificity. Numerous bands are usually unambiguously found in MS patients. The main technical problem is the ambiguity of faint OCB, which are hardly distinguishable from an IgG background, suggesting that techniques attenuating the IgG background may increase test sensitivity. Isoelectric focusing with affinity blotting against known antigens overcomes this limitation. In paraneoplastic syndromes devoid of intrathecal synthesis with classical techniques (OCB, IgG index), affinity blotting against $\mathrm{Hu}, \mathrm{Yo}$, or $\mathrm{GAD}$ antigens unmasks a specific intrathecal synthesis [62-64]. While affinity blotting gives qualitative results, only OCB restricted to CSF or more pronounced in CSF than in serum are discriminant. This technique improves specific antibody detection in CSF, but the specificity of intrathecally synthesized antibodies in MS is still unknown. Nevertheless, the presence of nonspecific intrathecal synthesis against the neurotropic viruses Measles, Rubella, and VZV (MRZ), commonly observed in MS for unclear reasons, appears very promising and gives a unique opportunity of qualitative and quantitative measures. MRZspecific OCB are present in the CSF of $72 \%$ of MS patients who otherwise fail to demonstrate OCB with IEF [65].

Specific antibody levels are more easily studied using the ELISA technique. The specific antibody index (AI) is a value calculated using the ratio of specific antibodies $Q_{\text {Spec }}$ $=\left[\operatorname{Spec}_{\mathrm{CSF}}\right] /\left[\mathrm{Spec}_{\text {serum }}\right]$ in the formula $\mathrm{AI}=\mathrm{Q}_{\mathrm{Spec}} / \mathrm{Q}_{\mathrm{IgG}}$, where AI values $>1.3-1.5$ represent an intrathecal synthesis. For example, high AI values are obtained in paraneoplastic syndrome (anti-GAD, -Hu syndromes) in the absence of apparent intrathecal synthesis (negative $\mathrm{OCB}$ and $\mathrm{Q}_{\mathrm{IgG}}<$ $\left.Q_{\text {Lim }}\right)[63,66]$. An MRZ pattern, defined by an elevated AI against $\geq 2$ neurotropic viruses, is observed in up to $90 \%$ of MS patients $[64,67]$. However, the AI is not usually assessed in patients with $Q_{\mathrm{IgG}}<Q_{\mathrm{Lim}}$ and negative OCB, because they are taken to be MRZ-negative since AI correlates with $Q_{\mathrm{IgG}}$ [61]. A systematic assessment for multiple AI (VZV, HSV, CMV, Measles, Rubella, and Borrelia) was undertaken in patients without apparent intrathecal synthesis $\left(Q_{\mathrm{IgG}}<\right.$ $Q_{\text {Lim }}$ and negative OCB). All but one of the 21 miscellaneous infectious and autoimmune patients had at least one elevated AI [61]. In MS patients without intrathecal synthesis, up to $47 \%$ of patients have $\geq 1$ elevated AI of MRZ pattern $[61,65,68-70]$. Interestingly, AI results are not completely congruent with those obtained by IEF with affinity blotting, increasing the prevalence of intrathecal synthesis detected by $\geq 1$ technique to $64 \%$ in the "CSF negative" subgroup of MS patients [65]. Acknowledging that MRZ reaction is common but not exclusive, and that reactions against many other viruses have been confirmed in MS (review in [71]), it may be expected that a larger antigenic test panel would improve the frequency of IT synthesis detection [61].

Free light-chains (FLC) are produced in excess by Igsecreting cells and are eliminated through renal clearance with a short plasma half-life (2-6 hours). Therefore, the very small amounts of FLC detectable in CSF are less contaminated by passive diffusion from blood. FLC assays in CSF and serum have been tested with various modes of calculation: absolute CSF concentration, $\kappa / \lambda$ ratio, and FLC index. FLC sensitivity seems to be near $100 \%$ but the (expected) specificity lower than OCB makes FLC less useful in diagnostic-purposed clinical routine $[72,73]$. However, FLC offers a simple and sensitive quantitative parameter, which appears suitable for monitoring intrathecal synthesis.

To our knowledge, no studies combining every technique in MS patients, especially those with "negative CSF," have been undertaken to date. Such studies performed with the more recent and sensitive laboratory methods would be the only definitive way to examine the prevalence of the true absence of intrathecal synthesis in MS, which is definitely less than $5 \%$. Moreover, we are unaware of such complete reports in non-Caucasian descent MS patients where OCB positivity is low $[74,75]$. Our short review argues for a probable faint intrathecal synthesis in the rare "CSF negative" patients. 
Nevertheless, common techniques (OCB and IgG index) are positive in more than 95\% of patients and Ig synthesis never disappears, making intrathecal synthesis the most valuable marker of MS to date.

Future studies dedicated to intrathecal synthesis may combine quantitative techniques ( $\operatorname{IgG}_{\mathrm{Loc}}$ or FLC) and highly sensitive qualitative techniques (OCB or MRZ pattern). Criteria for intrathecal Ig synthesis normalization should be based on simultaneous normalization of all the tests. In view of the fluctuations of intrathecal synthesis in individual patients (up to $30 \%$ of $\operatorname{IgG}_{\mathrm{Loc}}$ [76]), the demonstration of a drug action upon intrathecal synthesis should be statistically demonstrated in groups. Aiming at an intrathecal reset, a null Ig synthesis should be confirmed by multiple techniques.

\section{None of the Available MS Drugs Deplete Intrathecal Ig Synthesis}

4.1. Steroids. Various protocols of steroid infusions ranging from IV to intrathecal injections of various steroids have been described in the literature but none of them has demonstrated any sustained clinical success upon impairment [77].

In a series of 101 MS patients, CSF was drawn immediately before and after high-dosage steroid blood infusions $(1 \mathrm{~g} / \mathrm{d} / 10 \mathrm{~d})$ [78]. The proportion of patients having an elevated IgG index decreased from $93 \%$ before steroids to $84 \%$. IgM index positivity in $31 \%$ of patients was left unchanged (Table 1). OCB were found in $92 \%$ of patients and ОСВ count decreased from a mean of 5 to 4 in $82 \%$ of patients [78]. Improvement was only demonstrated in a questionable subgroup analysis. Comparable results were obtained in smaller series, sometimes showing a disassociation between a decrease in IgG synthesis and the preservation of $\mathrm{OCB}$ [79-83]. Multiple steroid dosages and various administration routes (intramuscular, intravenous, and intrathecal) had no effect upon OCB [84]. On the contrary, the intrathecal IgG synthesis rate dramatically decreased in all patients $(n=$ 22 ) and sometimes normalized (8/11 after IM ACTH gel) irrespective of the peripheral mode of steroid administration. However, a rebound occurred in a few months.

Intrathecal injections of steroids significantly but transiently depressed $\operatorname{IgG}$ synthesis in only 4 patients out of 7 but never normalized the IgG synthesis rate [84]. Even though steroids decreased the IgG index in most but not all patients, the decrease in CSF IgG synthesis was low and the CSF total protein concentration remained unaffected [79]. In a study including $54 \mathrm{MS}$ patients (either progressive or $\mathrm{RR}$ ), triamcinolone-acetonide ( $40-80 \mathrm{mg}$ ) was intrathecally infused 3-5 times over a week with a positive clinical outcome measured on clinical parameters, but CSF levels of NFL and S100 proteins showed minor changes and immunological parameters were not available [85].

4.2. Irradiation. Plasmablasts but not plasma cells are sensitive to irradiation. After irradiation (600-1800 rads) of the whole cerebrospinal axis of 19 MS patients over 4-17-day periods [81], only a transient drop in IgG synthesis rate was observed in 3/7 patients who received 1800 rads, without any effect upon clinical parameters. A combination of ACTH, brain irradiation, and daily prednisone given in 5 patients seemed to block IgG synthesis over a prolonged period and tended to persist after cessation [86]. However, even though CNS IgG synthesis failed in the normal range, the OCB pattern and free light-chains persisted [86].

4.3. Interferon Beta. Immunomodulatory therapies had no effect on CSF free light-chain levels [87]. Weekly $\beta$-IFN given intrathecally had no effect upon $\operatorname{IgG}_{\mathrm{Loc}}$ or $\mathrm{OCB}$ at 6 months [20]. In the phase III study of IFN- $\beta$ la, essentially no change occurred for IgG index or OCB in CSF drawn at 104 weeks [88]. This absence of effect upon IgG parameters was explained by the ability of IFN to stimulate in vivo expression of IL4 and secretion of IgG [88], but the absence of action upon plasma cell IgG secretion is more plausible.

4.4. Azathioprine. Azathioprine $(2-4.5 \mathrm{mg} / \mathrm{kg} / \mathrm{d})$ had no effect upon CSF IgG synthesis (IgG index and OCB pattern) after one year of treatment $[89,90]$. A decrease in the more elevated IgG indexes was observed but patients received steroids (at an active dose in the control group) and the control group had far lower pretherapy index values [90]. In a different study, quantitative IgG synthesis in patients treated by azathioprine did not differ from the control group with or without steroid treatment [91]. No change in CSF OCB and IgG level occurred in 8 patients treated by plasma exchange given in association with prednisolone and azathioprine [92].

4.5. Cytarabine (Intravenous or Intrathecal). Cytarabine (araC) is an antimetabolic agent interfering with DNA synthesis and is used in chemotherapeutic regimens for treating lymphomas. Cytotoxic levels administered in the systemic compartment do not achieve cytotoxic levels in the CSF, and reciprocally [93]. None of the 10 patients given cytarabine either systemically or intrathecally had changes in the number or pattern of CSF OCB. CNS IgG synthesis slightly decreased (about 10\%) after systemic infusion during the next month. However, CNS IgG synthesis transiently rose during the week following intrathecal administration, while at the same time CSF floating cells were low, and then all returned to their pretreatment level [93].

4.6. Lomustine. Lomustine (CCNU) is an alkylating agent used in neurooncology thanks to its high diffusibility in the CSF ( $50 \%$ of serum concentration) [94]. Given in a single oral dose at $130 \mathrm{mg} / \mathrm{m}^{2}$ in four patients, the IgG synthesis rate decreased by $-11 \%$ at weeks 2 and 4 and by $-20 \%$ at week 6 (statistically significant from baseline) [94].

4.7. 5-Fluorouracil (5-FU). 5-FU infused daily at $10 \mathrm{mg} / \mathrm{kg}$ in 3 patients for 5 days showed no effect upon IT IgG synthesis rate [94].

4.8. Methotrexate. No data is available about intrathecal Ig synthesis during methotrexate treatment given via the oral or IV route. Methotrexate is widely used via the CSF route in oncology and appears to be relatively safe. In a series of 121 progressive MS patients, intrathecal MTX 


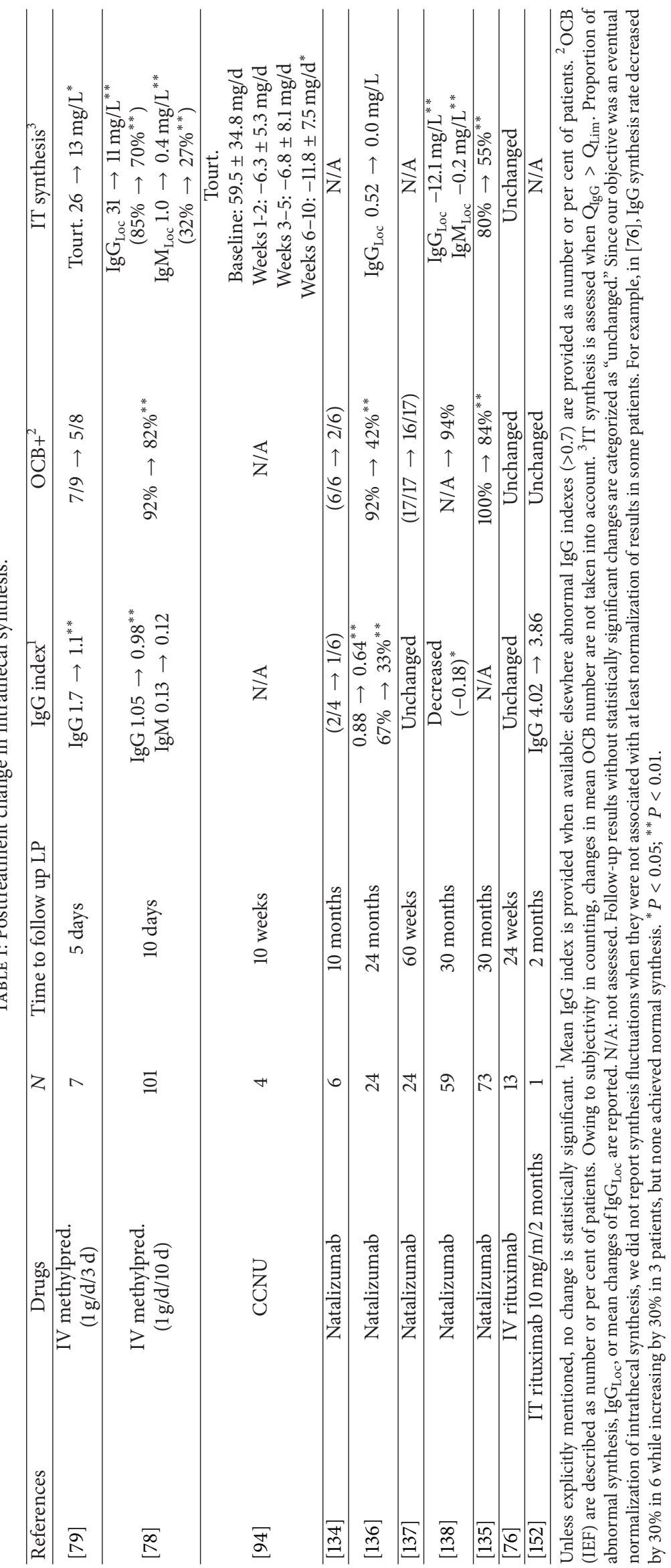


(12.5 mg/2 months/8 months) proved to be well tolerated [95]. A minor clinical effect was obtained, but in the absence of a control group these results should be considered with caution. Unfortunately, no data was gathered concerning an eventual modification of the CSF (OCB, cells, cytokines).

4.9. Cyclophosphamide. High-dosage cyclophosphamide (Суc) immunosuppression was used in protocols of autologous stem cell transplantation (see [96]). Cyc had a very minor effect upon the IgG index, interacting with the effect of steroids given as cotreatment [97, 98]. Cyc mainly targets $\mathrm{T}$-cells rather than B-cells, and Ig-secreting cells are considerably increased $(\times 4)$ in blood after Cyc treatment given without steroids, in association with a small increase $(\sim 20 \%)$ in Ig levels [99]. CSF IgG levels also increased but no data were given about intrathecal secretion [99]. Since the lipophilic properties of Cyc provide access to the CNS through the $\mathrm{BBB}, \mathrm{CSF}$ levels of Cyc are in the same range in blood and in CSF [100]. Although never investigated, such a paradoxical action may be expected in CSF, as is the case after intrathecal cytarabine infusion. In five patients receiving a daily IV dose of Cyc $(2.5-5 \mathrm{mg} / \mathrm{kg})$ for 10 days, CSF IgG synthesis decreased by $-11 \%$, which was not significantly different from baseline [94].

4.10. Cyclosporine A (CsA). CsA specifically decreases the biosynthesis of IgG [101]. CsA crosses the BBB with difficulty since levels of CsA varied between 300 and $500 \mathrm{ng} / \mathrm{mL}$ in blood and were under the test threshold $(30 \mathrm{ng} / \mathrm{mL})$ in CSF [102]. A two-year regimen of CsA (10 then $22 \mathrm{mg} / \mathrm{kg} / \mathrm{d}$ ) resulted in no change in free light-chains in nine patients [102]. In a two-center cohort including 82 patients, half receiving CsA, the IgG index was significantly decreased as compared to placebo in one center but not in the other one [103].

4.11. EBV-Specific Adoptive Immunotherapy. A single patient characterized by a blood CD8 T-cell deficiency and a blood EBV-specific CD8 T-cell deficiency (lower than 10th percentile compared to control patients) carrying HLA-A2 and HLA-B7 (which are restricting elements for several EBV epitopes used in this treatment) received autologous CD8+ Tcells activated against EBV [104]. Blood T-cells were collected from the patient, stimulated by AdE1-LMPpoly and IL2 and returned IV by gradual increasing dosage (from $5 \times 10^{6}$ to $2 \times 10^{7}$ cells). Intrathecal IgG secretion and the IgG index were normalized at month 4 [104]. This single case needs confirmation.

4.12. Mitoxantrone. Intrathecal IgG synthesis was assessed with a mean follow-up of $<2$ years in a series of $22 \mathrm{MS}$ patients treated with mitoxantrone [105]. No significant change in IgG index occurred during the follow-up. A modification in OCB bands was observed in 4/22 MS patients after 2 years of treatment, but changes were a gain of new bands in 2 patients or the loss and subsequent replacement of bands in other 2 . These changes did not differ from spontaneously occurring changes in untreated patients [105]. However, CXCL13 levels in the CSF at follow-up dropped to levels comparable to those of controls.

In a series of 28 RR-MS patients treated with the association of mitoxantrone $(20 \mathrm{mg})+$ rituximab $(1 \mathrm{~g})+$ methylprednisolone $(1 \mathrm{~g})$, the frequency and intensity of OCB remained unchanged at 12 months although CD19+ B-cells were profoundly depleted in the CSF [106].

4.13. Alemtuzumab. Alemtuzumab targets CD52, which is largely expressed in most lymphocytes, including B-cells but not plasma cells. Serum Ig levels are mostly unchanged after treatment although B-cells are completely depleted. Paired CSF samples available in 15 patients treated with alemtuzumab demonstrated the persistence of OCB following treatment [107].

4.14. Cladribine. Essentially no change in the OCB pattern and CSF IgG synthesis occurred after one year of treatment with cladribine [108].

4.15. Daclizumab. Daclizumab is a humanized anti-CD25 antibody with a pleotropic effect: expansion of CD $56^{\text {bright }} \mathrm{NK}$ cells, inhibition of T-cell activation by dendritic cells, and reduction in lymphoid tissue-inducer cells [109]. Daclizumab has a minimal effect on CSF lymphocyte count [110]. After 65 months of daclizumab therapy, the Ig index decreased by only $13 \%[111]$.

4.16. Fingolimod. Longitudinal CSF analysis during fingolimod treatment of MS patients showed that the cell count decreased (mean 8.3 to 1.8 cells $/ \mu \mathrm{L}$ ), while the IgG index, which was elevated in $4 / 7$ patients before, remained elevated in 2/8 afterwards and without any mean significant difference, whereas OCB persisted in all patients during follow-up [112].

4.17. Vitamin D. Low vitamin D levels are a risk factor for MS and for an unfavorable course of the disease. The median concentration of $25(\mathrm{OH}) \mathrm{D}$ was found to be $0.26 \mathrm{nM}$ in CSF and $61.5 \mathrm{nM}$ in blood [113]. CSF levels of 25(OH)D were lower than the in vitro concentration $(250 \mathrm{nM})$ necessary to affect B-cells $[114,115]$. However, in two studies with $40 \mathrm{MS}$ patients in each, neither serum nor intrathecal levels of vitamin D correlated with $\operatorname{IgG}$ index or presence of OCB $[113,116]$. In a series of $36 \mathrm{MS}$ patients, serum vitamin $\mathrm{D}$ correlated negatively with IgG index [117]. No data is available about the effect of vitamin D supplementation on intrathecal synthesis.

4.18. Autologous Stem Cell Transplantation. Autologous stem cell transplantation (HSCT) in MS provides a unique opportunity to dissect the remaining intrathecal inflammation. Combined myeloablative drugs completely abate the peripheral immune, nonspecifically targeting normal, autoimmune, and neoplastic components. Although HSCT could be expected to be effective in MS, it often fails to halt clinical progression [118-121], relapses [120, 122], and brain atrophy even in the absence of new inflammatory lesions $[96,121,123]$. In a postmortem study of MS patients treated by allogenic HSCT, acute demyelinating lesions and acute axonal 
degeneration persisted, [124-126] confirming the persistence of ongoing diffuse inflammation.

Receiver intrathecal inflammatory cells persist in CNS even after being completely abated in the periphery after HSCT. Marker of lymphocytes activation (sCD27) is elevated in CSF and only lowered after HSCT, confirming a persistent lymphocytic infiltration [122]. This process was dissected in a female patient having received bone marrow from a male donor and surviving 20 weeks [127]. A postmortem study based on in situ fluorescence hybridization performed for $\mathrm{X}$ and $\mathrm{Y}$ chromosomes in plaques distinguished male donor cells from female recipient T-cells. Male donor cells constituted only $3-17 \%$ of CD45 cells and $10 \%$ of CD68 macrophages, although all the blood cells originated from the male donor [127]. CD3+ T-cells from the donor were sparse in the parenchyma [127]. This case shows that most of the CNS inflammatory cell pool, which is not limited to nondividing plasma cells, is composed of resident resistant cells and that it seems poorly replenished from the periphery, at least in this context.

Multiple serum OCB usually develop during the first months following HSCT treatment, indicating the probable recapitulation of the B-cell ontogeny after grafting [128]. CSF OCB are rather stable after HSCT grafting: intrathecal pretreatment OCB mainly persists [121], although enriched by multiple OCB diffused from blood because of the disruption of the BBB [128]. In a study of 20 patients, 9 out of the 12 patients having OCB before HSCT were still positive after, and one OCB-negative patient at baseline gained OCB [96]. In a review of 34 HSCT patients, OCB persisted in $30 / 34$ patients while 2 out of the 10 who were initially OCB-negative became positive [122]. One case of SP-MS treated by a nonmyeloablative conditioning allo-HSCT for follicular lymphoma showed the disappearance of baseline OCB for four years, unlike CSF CXCL13 which changed from undetectable to detectable levels [129]. The failure to cure OCB is linked to the persistence of plasma cells rather than to a longer half-life of Ig in CSF [130] since their CSF clearance rate is extremely high. Immunoablation no more abates total blood Ig, IgG, or IgM against various common targets (i.e., myelin, influenza, and tetanus) [131]. This resistance is probably due to the intrinsic properties of long-lived plasma cells residing in bone marrow survival niches.

In conclusion, rigorous protocols aiming at the ablation of peripheral lymphocytes have always failed to abate intrathecal IgG synthesis significantly (Figure 1) and as is shown in what follows.

\section{Drug Action on Intrathecal IgG Synthesis}

No Action. Peripheral administration includes Irradiation, $\beta$-IFN conventional, Azathioprine, Cytarabine, Lomustine, 5-FU, Methotrexate, Cyclophosphamide, Cyclosporine A, Mitoxantrone, Alemtuzumab, Rituximab, Cladribine, Daclizumab, Fingolimod, Stem cell transplantation. Intrathecal route includes $\beta$-IFN, Cytarabine, Rituximab.

Decreasing Ig Synthesis. Peripheral administration includes steroids, natalizumab (conflicting reports), EBV-specific adoptive immunotherapy (needing confirmation). Intrathecal route includes steroids.

Normalizing Ig Synthesis. This was none (only transient effect of steroids).

\section{Partial Repression of Intrathecal IgG Synthesis by Natalizumab}

Natalizumab is a humanized monoclonal antibody directed against VLA-4, preventing leukocyte transmigration to CNS and inducing a sustained decline in all CSF leukocyte subsets up to 6-14 months after cessation of treatment. As soon as the first injection (5 days) of natalizumab and even 6 months after therapy cessation, CSF WBC, CD19+, CD4+ T-cells, CD8+ T-cells, and CD138+ plasma cells are lowered to the same level as those of controls-almost a null count [132]. At 6 months, CD4+ and CD8+ T-cells rose again in only one patient who relapsed [132]. Interestingly, not only T-cells are depleted in MS brain treated with natalizumab but also the same is true for B-cells and dendritic cells, which are usually increased in MS compared to controls [133]. The delayed onset of progressive multifocal leukoencephalopathy (PML) after the first year of natalizumab therapy suggests that the long-term uninterrupted use of natalizumab eventually leads to a reduction in dendritic cells to levels unable to prevent the onset of PML [133]. The number of doses needed to deplete dendritic cells from perivascular spaces, the maximal proportion of depletion that may be expected, and the time to reconstitute the pool after cessation are unknown [133].

In a series of 6 patients treated with natalizumab and positive for OCB before treatment (Table 1), 4/6 patients became OCB-negative (spinal tap controlled by a means of 10 infusions), whereas their IgG index increased in two of the four and dropped in the other two [134]. In a larger series of 76 patients, all the patients had OCB before natalizumab whereas $16 \%$ were found to be negative and the proportion of intrathecal synthesized IgG fraction (Reibergram) in the normal range increased from $20 \%$ to $45 \%$ [135]. In a study involving $24 \mathrm{MS}$ patients, the abnormal IgG index decreased from $67 \%$ to $33 \%$, the OCB positive pattern decreased from $92 \%$ to $42 \%$, and the mean $\operatorname{IgG}_{\text {Loc }}$ normalized [136]. Mean $\mathrm{IgG}_{\mathrm{Loc}}$ was unusually low in this study (mean $0.5 \mathrm{mg} / \mathrm{L}$, max. $2.4 \mathrm{mg} / \mathrm{L}$ ), which may have biased results toward a high suppressive effect [136]. These results suggest that intrathecal secretion is merely repressed rather than suppressed by natalizumab. In another study including 17 patients, although a minor effect was observed on OCB and IgG index, the changes were not significant at one year [137]. OCB remained detectable in the majority (94\%) of 52 patients included in a cross-sectional study [138]. However, a statistically significant but small decrease in $\operatorname{IgG}_{\text {Loc }}$ and IgG index was observed [138]. AI to MRZ, which was tested in 6 patients, also declined in three of them and remained below the limit in the other three [138].

The repression of IgG synthesis in the intrathecal compartment by natalizumab, which was highly unexpected and paradoxical, deserves three nonmutually exclusive explanations. First, $\alpha 4 \beta 1$-integrin is expressed not only by Tcells but also by B-cells (CD19+ and CD138+) and CD14+ 

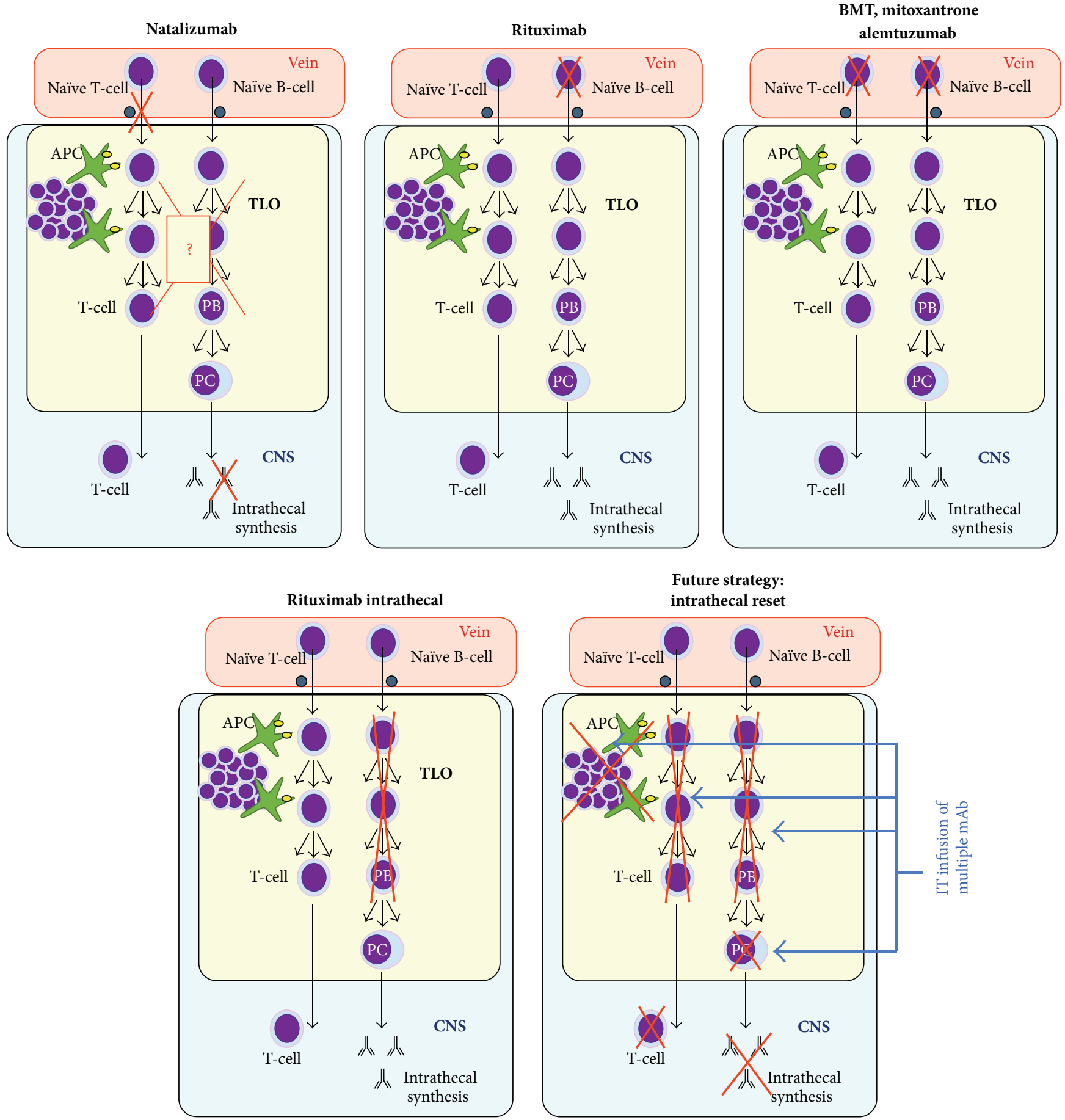

FIGURE 1: Schematic targets of MS treatments upon CNS compartmentalized inflammation, especially in tertiary lymphoid organs (TLO). Except for natalizumab (owing to unclear mechanisms), none of the treatments targeting blood B-cells have shown any action upon intrathecal IgG synthesis. Preliminary results suggest that rituximab also fails to reduce IgG synthesis. Future treatment strategies might be redirected to reset all the components of intrathecally compartmentalized inflammation. APC: antigen-presenting cells; BMT: bone marrow transplant; PB/PC: plasmablasts/plasma cells; TLO: tertiary lymphoid organs.

monocytes at higher levels than CD3+ T-cells $[139,140]$. As a consequence, B-cell trafficking to the brain is highly impeded by natalizumab and the renewal of the CNS plasmablast pool may also be highly impeded, ultimately leading to the nonrenewal and flush of the terminally differentiated plasma cell pool. Blood retention of lymphocytes after initiation of natalizumab is even disproportionately increased more for CD19+ B-cells than for CD3+ T-cells [140, 141], but this is probably better explained by a purge effect on lymphoid progenitors from bone marrow than by the inhibition of 
the transmigration of small lymphocytes to the CNS [141]. Secondly, plasma cells survive in niches where they interact with cytokines, and T-cells may also play a supportive survival role among the surrounding cells [45]. Moreover, natalizumab flushes MZ-B-cells from secondary lymphoid organs [141], but whether it has an effect on intrathecal lymphoid tissue cells is unknown. Thirdly, natalizumab inhibits the CNS migration of dendritic cells, which in turn may affect the maintenance of CNS lymphoid tissue [142]. Of note, a significant decrease in IgM (and less significantly in IgG) plasma levels also occurs during natalizumab treatment but is not correlated with treatment duration, suggesting that this drug effectively perturbs the IgG synthesis pathway $[138,143]$.

Future experiments should examine whether patients who have normalized intrathecal IgG secretion and then discarded natalizumab may regain this secretion. Data obtained from a single patient devoid of OCB under natalizumab and withdrawing treatment for PML showed that OCB shortly returned with a slightly modified pattern [134], whereas a sustained negativation was observed at 6 months in two other patients [135].

\section{Rituximab Depletes CSF B-Cells without Modifying Intrathecal IgG Synthesis}

Rituximab is an IgG1K monoclonal antibody targeting CD20 by multiple and synergistic mechanisms: apoptosis, complement-mediated cell lysis, and antibody-dependent cellular toxicity. All the B-cells expressing high levels of CD20 $\left(\mathrm{CD} 20^{\text {bright }}\right)$ and a subfraction of CD20+ T-cells are targeted, whereas a minor population of B-cells expressing a lower concentration of CD19 (CD19 $\left.9^{\mathrm{dim}}\right)$ may resist rituximabeven more so at low concentrations-and expand during reconstitution [144]. Plasma cells, which do not express CD20 but secrete high levels of Ig, are fully resistant.

In a single MS case receiving rituximab infusion in blood, CD19+ B-cells were completely depleted from blood and CSF at 8 weeks and 6 months [145]. In another case studied for CSF at 7 time points, $\mathrm{CD} 138+$ disappeared after the first infusion until month 7; CD19+ and CD20+ decreased from 3\% to $0.25 \%$ after the first infusion and then disappeared before month 4 only to reappear briefly at month $5(0.2-0.4 \%)$ and then disappeared again until month 10 [146]. By contrast in blood, CD20+ cells and CD138+ cells, which completely disappeared before the fourth infusion, reappeared at month 10 [146]. In a study of $22 \mathrm{MS}$ patients, CSF was compared before and 24 weeks after IV rituximab [147]. CD19+ and CD3+ cells decreased in CSF but did not completely disappear [147]. The two cytokines CXCL13 and CCL19 decreased in CSF at week 24 compared to baseline, but CXCL10 remained unchanged [147]. In a phase II clinical trial, 16 RR-MS patients were treated by rituximab and were investigated one week prior to and 24 weeks after infusion [76]. In CSF, the CD19+ Bcell count decreased by $90 \%$ and the CD3+ T-cell count by $50 \%$. However, the CSF IgG level, IgG index, and OCB number remained essentially unchanged since the overall mean reduction in IgG synthesis of $21 \%$ was not statistically significant $[76,147]$. In another study (phase II/III trial in
PPMS), a minor depletion of CSF CD19+ B-cells was achieved in some patients $(1 / 4)$ but never to the same extent as in blood [144]. When a second infusion of rituximab was given, the CSF CD19+ cell count no longer dropped either in blood or in CSF [144]. In fact, this failure to lower the intrathecal IgG secretion was predictable from the absence of effect of bloodinfused rituximab upon serum IgG and IgA levels, contrary to a minor effect upon IgM levels $[76,148]$.

Rituximab concentration in CSF does not exceed $0.2 \%$ of its concentration in serum, and repetitive infusions in blood fail to increase its CSF concentration [149, 150]. Given the low diffusion of rituximab in CSF and a growing body of evidence demonstrating the safe use of intrathecally infused rituximab, a rationale to infuse intrathecal rituximab in progressive MS recently emerged. Data obtained from a single patient receiving intrathecal rituximab (10 mg each month for 2 months) showed a major effect upon CSF cytokine levels (especially TNF $\alpha$, IL2, IL15, and CXCL10), although intrathecal IgG synthesis was unchanged $[151,152]$. These preliminary results deserve further studies and two trials using intrathecal rituximab either alone or associated with intravenous infusion are now recruiting (RIVITaLISE: NCT01212094, ITT-PMS: NCT01719159, in https://www.clinicaltrials.gov/, last access in August 2014). Many aspects of intrathecal rituximab infusion are to be clarified concerning its biological and clinical effects and optimized administration protocols. For example, should the intrathecal route be used alone or associated with blood infusion? Are multiple intrathecal infusions to be scheduled? Do repeated infusions reduce intrathecal IgG synthesis in the long term? Future trials should deal with these pending questions.

\section{Targeting Intrathecal IgG Synthesis: A Whole New Paradigm in Treating MS}

Intrathecal $\operatorname{IgG}$ synthesis appears to be partly sensitive to steroids but never abates completely. Since the 70s, authors have hypothesized the existence of two populations of IgG secretory cells that differ in their sensitivity to steroids [80, 153]: one population of B-cells continuously recruited via the attraction of chemotactic factors might be downregulated by steroids, whereas the other population of plasma cells might permanently reside inside the CNS and resist steroids and irradiation $[86,153]$. This hypothesis was further supported by the demonstration of a dual population of CNS IgG secreting B-cells: short-lived (days to weeks) fully differentiated plasmablasts retaining their capacity to divide and long-lived (years to decades) plasma cells unable to proliferate.

Some blood-infused treatments have been demonstrated to decrease CSF B-cell levels. For example, B-cell count decreases by $90 \%$ after blood infusion of rituximab whereas IgG synthesis remains essentially unchanged. This dissociation suggests that B-cell depletion mainly concerns plasmablasts and CSF floating cells whereas most of the parenchymal residing B-cells (probably plasma cells) remain and secrete IgG. The small decrease in intrathecal IgG synthesis observed after natalizumab is not the consequence of a simple interruption of B-cell traffic into the CNS: traffic is interrupted both after natalizumab and after rituximab infusion, 
either by traffic blockade or by destruction of blood B-cells. Natalizumab probably provides an additional condition (see above) favoring the attrition of CNS plasmablasts and/or plasma cells. Whatever the exact cause and the duration of the effect are, the few MS patients losing intrathecal synthesis after steroids or natalizumab provide the proof of concept that intrathecal IgG synthesis is reversible in MS. Intrathecal infusion of rituximab might overcome the BBB problem and CSF plasmablasts but no plasma cells are expected to be completely eliminated from the CNS. Results of ongoing trials will clarify whether CNS plasmablasts are resistant to rituximab as observed in synovial tertiary lymphoid organs of rheumatoid arthritis and decipher which B-cell subpopulation drives intrathecal IgG synthesis.

Moreover, it has long been thought that the progressive phase of MS is driven by neurodegenerative processes since the compartmentalized inflammation consistently resists immunosuppressive strategies. In our opinion, this point of view cannot be validated until a long-lasting eradication of the CNS immune reaction is obtained. Only after this goal is achieved we will be in a position to assess the possible benefits of immunosuppression in MS [86]. Future therapeutic strategies (Figure 1) may target each component of intrathecally compartmentalized autoimmunity with a "magic bullet" (Ehrlich) associating a few of monoclonal antibodies against key targets, including plasma cells [1]. Depending on the primary antigenic stimulation, the estimated half-life of longlived plasma cells varies from a decade to one hundred years, and prolonged survival depends on antiapoptotic factors provided by cell niches [154]. Plasma cells expelled from survival niches during competition challenges undergo apoptosis $[154,155]$. As a consequence, it cannot be expected that a complete attrition of the terminally differentiated plasma cells residing inside the CNS could be attained in a human life time with road-blocking therapies. Rather, future therapies should also target CNS-resident plasma cells [1].

Intrathecal IgG synthesis is a key characteristic of MS that, once installed at the onset of MS, never fails or abates. Intrathecal IgG synthesis is present in almost every MS patient unlike other CSF markers, which are elevated only in a subset of patients. For example, mean levels of common markers like soluble sCD27 (a marker of T-cell activation), neurofilament light-chain (marker of neurodegeneration), and CXCL13/CXCL10 (attractive cytokines for B-cells) are all elevated in MS series but remain normal in a large proportion of individual MS patients. On the other hand, IgG synthesis (BOC or IgG index) is always elevated in MS patients and intrathecal IgG level normalization is a goal yet to be attained with treatments. Moreover, a major decrease in intrathecal IgG synthesis, which recapitulates the terminal function of Ig-secreting cells, should be more predictive of an intraparenchymal depletion of the B-cell population. We consider that normalization of intrathecal IgG synthesis, which is easily assessed by spinal tap, could be the main goal in future therapeutic trials targeting intrathecal inflammation. Future work should attempt to decipher whether the normalization of intrathecal synthesis might be predictive of clearance of CNS inflammation and could be associated with MS remission.

\section{Conflict of Interests}

The author declares that there is no conflict of interests regarding the publication of this paper.

\section{Acknowledgment}

The author is indebted to R. Cooke for copyediting.

\section{References}

[1] M. Bonnan, "Intrathecal immune reset in multiple sclerosis: exploring a new concept," Medical Hypotheses, vol. 82, no. 3, pp. 300-309, 2014.

[2] H. Reiber, S. Ungefehr, and C. Jacobi, "The intrathecal, polyspecific and oligoclonal immune response in multiple sclerosis," Multiple Sclerosis, vol. 4, no. 3, pp. 111-117, 1998.

[3] V. K. Kostulas, H. Link, and A. K. Lefvert, "Oligoclonal IgG bands in cerebrospinal fluid. Principles for demonstration and interpretation based on findings in 1114 neurological patients," Archives of Neurology, vol. 44, no. 10, pp. 1041-1044, 1987.

[4] A. Ghezzi, C. Pozzilli, M. Liguori et al., "Prospective study of multiple sclerosis with early onset," Multiple Sclerosis, vol. 8, no. 2, pp. 115-118, 2002.

[5] D. Pohl, K. Rostasy, H. Reiber, and F. Hanefeld, "CSF characteristics in early-onset multiple sclerosis," Neurology, vol. 63, no. 10, pp. 1966-1967, 2004.

[6] S. Siritho and M. S. Freedman, "The prognostic significance of cerebrospinal fluid in multiple sclerosis," Journal of the Neurological Sciences, vol. 279, no. 1-2, pp. 21-25, 2009.

[7] A. Z. J. Zeman, D. Kidd, B. N. McLean et al., "A study of oligoclonal band negative multiple sclerosis," Journal of Neurology, Neurosurgery, and Psychiatry, vol. 60, no. 1, pp. 2730, 1996.

[8] A. Sena, P. Rosado, V. Ferret-Sena, J. Coimbra, E. Schuller, and C. J. M. Sindic, "Multiple sclerosis and intrathecal IgA synthesis," Acta Neurologica Belgica, vol. 97, no. 1, pp. 36-38, 1997.

[9] F. Lolli, I. Halawa, and H. Link, "Intrathecal synthesis of IgG, IgA, IgM and IgD in untreated multiple sclerosis and controls," Acta Neurologica Scandinavica, vol. 80, no. 3, pp. 238-247, 1989.

[10] S. Goffette, M. Schluep, H. Henry, T. Duprez, and C. J. M. Sindic, "Detection of oligoclonal free kappa chains in the absence of oligoclonal IgG in the CSF of patients with suspected multiple sclerosis," Journal of Neurology, Neurosurgery \& Psychiatry, vol. 75, no. 2, pp. 308-310, 2004.

[11] Y. Qin, P. Duquette, Y. Zhang et al., "Intrathecal B-cell clonal expansion, an early sign of humoral immunity, in the cerebrospinal fluid of patients with clinically isolated syndrome suggestive of multiple sclerosis," Laboratory Investigation, vol. 83, no. 7, pp. 1081-1088, 2003.

[12] C. Harp, J. Lee, D. Lambracht-Washington et al., "Cerebrospinal fluid B cells from multiple sclerosis patients are subject to normal germinal center selection," Journal of Neuroimmunology, vol. 183, no. 1-2, pp. 189-199, 2007.

[13] M. J. Walsh and W. W. Tourtellotte, “Temporal invariance and clonal uniformity of brain and cerebrospinal IgG, IgA, and IgM in multiple sclerosis," The Journal of Experimental Medicine, vol. 163, no. 1, pp. 41-53, 1986.

[14] L. M. Villar, J. Masjuan, P. González-Porqué et al., "Intrathecal IgM synthesis is a prognostic factor in multiple sclerosis," Annals of Neurology, vol. 53, no. 2, pp. 222-226, 2003. 
[15] C. Stauch, H. Reiber, M. Rauchenzauner et al., "Intrathecal IgM synthesis in pediatric MS is not a negative prognostic marker of disease progression: quantitative versus qualitative IgM analysis," Multiple Sclerosis, vol. 17, no. 3, pp. 327-334, 2011.

[16] B. Kuenz, A. Lutterotti, R. Ehling et al., "Cerebrospinal fluid $B$ cells correlate with early brain inflammation in multiple sclerosis," PLoS ONE, vol. 3, no. 7, Article ID e2559, 2008.

[17] L. M. Villar, T. Masterman, B. Casanova et al., "CSF oligoclonal band patterns reveal disease heterogeneity in multiple sclerosis," Journal of Neuroimmunology, vol. 211, no. 1-2, pp. 101-104, 2009.

[18] T. Derfuss, R. Gürkov, F. T. Bergh et al., "Intrathecal antibody production against Chlamydia pneumoniae in multiple sclerosis is part of a polyspecific immune response," Brain, vol. 124, no. 7, pp. 1325-1335, 2001.

[19] X. Yu, M. Burgoon, M. Green et al., "Intrathecally synthesized IgG in multiple sclerosis cerebrospinal fluid recognizes identical epitopes over time," Journal of Neuroimmunology, vol. 240-241, pp. 129-136, 2011.

[20] C. Confavreux, C. Chapuis-Cellier, P. Arnaud, O. Robert, G. Aimard, and M. Devic, "Oligoclonal 'fingerprint' of CSF IgG in multiple sclerosis patients is not modified following intrathecal administration of natural beta-interferon," Journal of Neurology Neurosurgery and Psychiatry, vol. 49, no. 11, pp. 1308-1312, 1986.

[21] W. W. Tourtellotte, R. W. Baumhefner, K. Syndulko et al., "The long march of the cerebrospinal fluid profile indicative of clinical definite multiple sclerosis; and still marching," Journal of Neuroimmunology, vol. 20, no. 2-3, pp. 217-227, 1988.

[22] E. M. Cameron, S. Spencer, J. Lazarini et al., "Potential of a unique antibody gene signature to predict conversion to clinically definite multiple sclerosis," Journal of Neuroimmunology, vol. 213, no. 1-2, pp. 123-130, 2009.

[23] A. J. Ligocki, L. Lovato, D. Xiang et al., "A unique antibody gene signature is prevalent in the central nervous system of patients with multiple sclerosis," Journal of Neuroimmunology, vol. 226, no. 1-2, pp. 192-193, 2010.

[24] R. Magliozzi, S. Columba-Cabezas, B. Serafini, and F. Aloisi, "Intracerebral expression of CXCL13 and BAFF is accompanied by formation of lymphoid follicle-like structures in the meninges of mice with relapsing experimental autoimmune encephalomyelitis," Journal of Neuroimmunology, vol. 148, no. 1-2, pp. 11-23, 2004.

[25] O. W. Howell, C. A. Reeves, R. Nicholas et al., "Meningeal inflammation is widespread and linked to cortical pathology in multiple sclerosis," Brain, vol. 134, no. 9, pp. 2755-2771, 2011.

[26] E. Meinl, M. Krumbholz, and R. Hohlfeld, "B lineage cells in the inflammatory central nervous system environment: migration, maintenance, local antibody production, and therapeutic modulation," Annals of Neurology, vol. 59, no. 6, pp. 880-892, 2006.

[27] M. Haugen, J. L. Frederiksen, and M. Degn, "B cell follicle-like structures in multiple sclerosis-with focus on the role of B cell activating factor," Journal of Neuroimmunology, vol. 273, no. 1-2, pp. 1-7, 2014.

[28] M. Bonnan, “Organes lymphoïdes tertiaires méningés: des acteurs majeurs de l'utoimmunité intrathécale," Accepté Revue Neurologique.

[29] L. Lovato, S. N. Willis, S. J. Rodig et al., "Related B cell clones populate the meninges and parenchyma of patients with multiple sclerosis," Brain, vol. 134, no. 2, pp. 534-541, 2011.

[30] G. Skorstad, B. Vandvik, F. Vartdal, and T. Holmøy, "MS and clinically isolated syndromes: shared specificity but diverging clonal patterns of virus-specific IgG antibodies produced in vivo and by CSF B cells in vitro," European Journal of Neurology, vol. 16, no. 10, pp. 1124-1129, 2009.

[31] A. Junker, J. Ivanidze, J. Malotka et al., "Multiple sclerosis: T-cell receptor expression in distinct brain regions," Brain, vol. 130, no. 11, pp. 2789-2799, 2007.

[32] M. Colombo, M. Dono, P. Gazzola et al., "Accumulation of clonally related B lymphocytes in the cerebrospinal fluid of multiple sclerosis patients," The Journal of Immunology, vol. 164, no. 5, pp. 2782-2789, 2000.

[33] H.-C. von Büdingen, T. C. Kuo, M. Sirota et al., "B cell exchange across the blood-brain barrier in multiple sclerosis," Journal of Clinical Investigation, vol. 122, no. 12, pp. 4533-4543, 2012.

[34] S. Kuerten, A. Schickel, C. Kerkloh et al., “Tertiary lymphoid organ development coincides with determinant spreading of the myelin-specific T cell response," Acta Neuropathologica, vol.124, no. 6, pp. 861-873, 2012.

[35] R. Reynolds, F. Roncaroli, R. Nicholas, B. Radotra, D. Gveric, and O. Howell, "The neuropathological basis of clinical progression in multiple sclerosis," Acta Neuropathologica, vol. 122, no. 2, pp. 155-170, 2011.

[36] H.-C. von Büdingen, M. D. Harrer, S. Kuenzle, M. Meier, and N. Goebels, "Clonally expanded plasma cells in the cerebrospinal fluid of MS patients produce myelin-specific antibodies," European Journal of Immunology, vol. 38, no. 7, pp. 2014-2023, 2008.

[37] E. Beltrán, A. Hernández, E. M. Lafuente et al., "Neuronal antigens recognized by cerebrospinal fluid $\operatorname{IgM}$ in multiple sclerosis," Journal of Neuroimmunology, vol. 247, no. 1-2, pp. 6369, 2012.

[38] C. Elliott, M. Lindner, A. Arthur et al., "Functional identification of pathogenic autoantibody responses in patients with multiple sclerosis," Brain, vol. 135, no. 6, pp. 1819-1833, 2012.

[39] D. Zhou, R. Srivastava, S. Nessler et al., "Identification of a pathogenic antibody response to native myelin oligodendrocyte glycoprotein in multiple sclerosis," Proceedings of the National Academy of Sciences of the United States of America, vol. 103, no. 50, pp. 19057-19062, 2006.

[40] J. Fraussen, N. Claes, L. de Bock, and V. Somers, "Targets of the humoral autoimmune response in multiple sclerosis," Autoimmunity Reviews, vol. 13, no. 11, pp. 1126-1137, 2014.

[41] R. P. Lisak, J. A. Benjamins, L. Nedelkoska et al., "Secretory products of multiple sclerosis B cells are cytotoxic to oligodendroglia in vitro," Journal of Neuroimmunology, vol. 246, no. 1-2, pp. 85-95, 2012.

[42] A. J. Steelman and J. Li, "Poly(I:C) promotes TNF $\alpha /$ TNFR1dependent oligodendrocyte death in mixed glial cultures," Journal of Neuroinflammation, vol. 8, article 89, 2011.

[43] K. Selmaj and C. S. Raine, "Tumor necrosis factor mediates myelin damage in organotypic cultures of nervous tissue," Annals of the New York Academy of Sciences, vol. 540, pp. 568$570,1988$.

[44] H. L. Wilson, "B cells contribute to MS pathogenesis through antibody-dependent and antibody-independent mechanisms," Biologics: Targets and Therapy, vol. 6, pp. 117-123, 2012.

[45] D. R. Withers, C. Fiorini, R. T. Fischer, R. Ettinger, P. E. Lipsky, and A. C. Grammer, "T cell-dependent survival of $\mathrm{CD} 20^{+}$and CD20- plasma cells in human secondary lymphoid tissue," Blood, vol. 109, no. 11, pp. 4856-4864, 2007.

[46] A. Bar-Or, L. Fawaz, B. Fan et al., "Abnormal B-cell cytokine responses a trigger of T-cell-mediated disease in MS?" Annals of Neurology, vol. 67, no. 4, pp. 452-461, 2010. 
[47] R. Magliozzi, O. Howell, A. Vora et al., "Meningeal B-cell follicles in secondary progressive multiple sclerosis associate with early onset of disease and severe cortical pathology," Brain, vol. 130, no. 4, pp. 1089-1104, 2007.

[48] M. Vercellino, F. Plano, B. Votta, R. Mutani, M. T. Giordana, and P. Cavalla, "Grey matter pathology in multiple sclerosis," Journal of Neuropathology and Experimental Neurology, vol. 64, no. 12, pp. 1101-1107, 2005.

[49] A. Kutzelnigg, C. F. Lucchinetti, C. Stadelmann et al., "Cortical demyelination and diffuse white matter injury in multiple sclerosis," Brain, vol. 128, no. 11, pp. 2705-2712, 2005.

[50] A. Kutzelnigg, J. C. Faber-Rod, J. Bauer et al., "Widespread demyelination in the cerebellar cortex in multiple sclerosis," Brain Pathology, vol. 17, no. 1, pp. 38-44, 2007.

[51] C. P. Gilmore, I. Donaldson, L. Bö, T. Owens, J. Lowe, and N. Evangelou, "Regional variations in the extent and pattern of grey matter demyelination in multiple sclerosis: A comparison between the cerebral cortex, cerebellar cortex, deep grey matter nuclei and the spinal cord," Journal of Neurology, Neurosurgery and Psychiatry, vol. 80, no. 2, pp. 182-187, 2009.

[52] S. R. Choi, O. W. Howell, D. Carassiti et al., "Meningeal inflammation plays a role in the pathology of primary progressive multiple sclerosis," Brain, vol. 135, no. 10, pp. 2925-2937, 2012.

[53] M. S. Freedman, E. J. Thompson, F. Deisenhammer et al., "Recommended standard of cerebrospinal fluid analysis in the diagnosis of multiple sclerosis: a consensus statement," Archives of Neurology, vol. 62, no. 6, pp. 865-870, 2005.

[54] G. Davies, G. Keir, E. J. Thompson, and G. Giovannoni, “The clinical significance of an intrathecal monoclonal immunoglobulin band: a follow-up study," Neurology, vol. 60, no. 7, pp. 11631166, 2003.

[55] W. W. Tourtellotte, A. R. Potvin, J. O. Fleming et al., "Multiple sclerosis: measurement and validation of central nervous system IgG synthesis rate," Neurology, vol. 30, no. 3, pp. 240-244, 1980.

[56] B. Delpech and E. Lichtblau, "Immunochemical estimation of IgG and albumin in cerebrospinal fluid," Clinica Chimica Acta, vol. 37, no. C, pp. 15-23, 1972.

[57] G. Tibbling, H. Link, and S. Ohman, "Principles of albumin and IgG analyses in neurological disorders. I. Establishment of reference values," Scandinavian Journal of Clinical and Laboratory Investigation, vol. 37, no. 5, pp. 385-390, 1977.

[58] H. Reiber and P. Lange, "Quantification of virus-specific antibodies in cerebrospinal fluid and serum: sensitive and specific detection of antibody synthesis in brain," Clinical Chemistry, vol. 37, no. 7, pp. 1153-1160, 1991.

[59] H. Reiber, M. Teut, D. Pohl, K. M. Rostasy, and F. Hanefeld, "Paediatric and adult multiple sclerosis: age-related differences and time course of the neuroimmunological response in cerebrospinal fluid," Multiple Sclerosis, vol. 15, no. 12, pp. 1466-1480, 2009.

[60] M. Andersson, J. Alvarez-Cermeno, G. Bernardi et al., "Cerebrospinal fluid in the diagnosis of multiple sclerosis: a consensus report," Journal of Neurology Neurosurgery \& Psychiatry, vol. 57, no. 8, pp. 897-902, 1994.

[61] S. Jarius, P. Eichhorn, B. Wildemann, and M. Wick, "Usefulness of antibody index assessment in cerebrospinal fluid from patients negative for total-IgG oligoclonal bands," Fluids and Barriers of the CNS, vol. 9, no. 1, article 14, 2012.

[62] O. Stich, F. Graus, C. Rasiah, and S. Rauer, "Qualitative evidence of anti-Yo-specific intrathecal antibody synthesis in patients with paraneoplastic cerebellar degeneration," Journal of Neuroimmunology, vol. 141, no. 1-2, pp. 165-169, 2003.

[63] S. Jarius, O. Stich, J. Speck et al., "Qualitative and quantitative evidence of anti-glutamic acid decarboxylase-specific intrathecal antibody synthesis in patients with stiff person syndrome," Journal of Neuroimmunology, vol. 229, no. 1-2, pp. 219-224, 2010.

[64] S. Jarius, D. Franciotta, R. Bergamaschi et al., "Polyspecific, antiviral immune response distinguishes multiple sclerosis and neuromyelitis optica," Journal of Neurology, Neurosurgery and Psychiatry, vol. 79, no. 10, pp. 1134-1136, 2008.

[65] O. Stich, J. Kluge, J. Speck, and S. Rauer, “Oligoclonal restriction of antiviral immunoreaction in oligoclonal band-negative MS patients," Acta Neurologica Scandinavica, 2014.

[66] O. Stich, S. Jarius, B. Kleer, C. Rasiah, R. Voltz, and S. Rauer, "Specific antibody index in cerebrospinal fluid from patients with central and peripheral paraneoplastic neurological syndromes," Journal of Neuroimmunology, vol. 183, no. 1-2, pp. 220 224, 2007.

[67] J. Bednářová, P. Štourač, and P. Adam, "Relevance of immunological variables in neuroborreliosis and multiple sclerosis," Acta Neurologica Scandinavica, vol. 112, no. 2, pp. 97-102, 2005.

[68] J. L. Frederiksen and C. J. M. Sindic, "Intrathecal synthesis of virus-specific oligoclonal IgG, and of free kappa and free lambda oligoclonal bands in acute monosymptomatic optic neuritis. Comparison with brain MRI," Multiple Sclerosis, vol. 4, no. 1, pp. 22-26, 1998.

[69] O. Stich, J. Kluge, J. Speck, and S. Rauer, "Detection of virusspecific (measles, rubella, zoster) oligoclonal IgG-bands in CSF from multiple sclerosis patients without oligoclonal bands of total IgG," Multiple Sclerosis Journal, vol. 15, p. S86, 2009.

[70] I. Brecht, B. Weissbrich, J. Braun, K. V. Toyka, A. Weishaupt, and M. Buttmann, "Intrathecal, polyspecific antiviral immune response in oligoclonal band negative multiple sclerosis," PLoS ONE, vol. 7, no. 7, Article ID e40431, 2012.

[71] M. Bonnan, "Does disease-irrelevant intrathecal synthesis in multiple sclerosis make sense in the light of tertiary lymphoid organs?" Frontiers in Neurology, vol. 5, article 27, 2014.

[72] B. Kaplan, B. M. Aizenbud, S. Golderman, R. Yaskariev, and B.A. Sela, "Free light chain monomers in the diagnosis of multiple sclerosis," Journal of Neuroimmunology, vol. 229, no. 1-2, pp. 263-271, 2010.

[73] C. J. M. Sindic and E. C. Laterre, "Oligoclonal free kappa and lambda bands in the cerebrospinal fluid of patients with multiple sclerosis and other neurological diseases. An immunoaffinity-mediated capillary blot study," Journal of Neuroimmunology, vol. 33, no. 1, pp. 63-72, 1991.

[74] P. Cabre, O. Heinzlef, H. Merle et al., "MS and neuromyelitis optica in Martinique (French West Indies)," Neurology, vol. 56, no. 4, pp. 507-514, 2001.

[75] S. Yoshimura, N. Isobe, T. Matsushita et al., "Genetic and infectious profiles influence cerebrospinal fluid IgG abnormality in japanese multiple sclerosis patients," PLoS ONE, vol. 9, no. 4, Article ID e95367, 2014.

[76] A. H. Cross, J. L. Stark, J. Lauber, M. J. Ramsbottom, and J.-A. Lyons, "Rituximab reduces B cells and T cells in cerebrospinal fluid of multiple sclerosis patients," Journal of Neuroimmunology, vol. 180, no. 1-2, pp. 63-70, 2006.

[77] R. Heun, U. Sliwka, H. Ruttinger, and K. Schimrigk, "Intrathecal versus systemic corticosteroids in the treatment of multiple sclerosis: results of a pilot study," Journal of Neurology, vol. 239, no. 1, pp. 31-35, 1992. 
[78] S. T. F. M. Frequin, F. Barkhof, K. J. B. Lamers, O. R. Hommes, and G. F. Borm, "CSF myelin basic protein, IgG and IgM levels in 101 MS patients before and after treatment with high-dose intravenous methylprednisolone," Acta Neurologica Scandinavica, vol. 86, no. 3, pp. 291-297, 1992.

[79] J. L. Trotter and W. F. Garvey, "Prolonged effects of large-dose methylprednisolone infusion in multiple sclerosis," Neurology, vol. 30, no. 7, pp. 702-708, 1980.

[80] R. W. Baumhefner, M. M. Booe, and W. W. Tourtellotte, "Modulation of de novo CNS IgG synthesis with preservation of oligoclonal IgG in multiple sclerosis," Neurology, vol. 29, p. $549,1979$.

[81] W. W. Tourtellotte, K. Murthy, D. Brandes, J. Jurkowitz, and J. O. Fleming, "Immunosuppressive therapy of multiple sclerosis: I. Further studies with X-irradiation of central nervous system," Neurology, vol. 25, supplement, pp. 362-363, 1975.

[82] A. R. Massaro, "Modifications of the cerebrospinal fluid IgG concentrations in patients with multiple sclerosis treated with intrathecal steroids," Journal of Neurology, vol. 219, no. 4, pp. 221-226, 1978.

[83] W. Elsner, W. W. Tourtellotte, K. Murthy, M. M. Booe, A. Potvin, and K. Syndulko, "Multiple sclerosis: effect of dexamethasone on in situ central nervous system IgG synthesis," Neurology, p. 403, 1978.

[84] W. E. Tourtellotte, R. W. Baumhefner, A. R. Potvin, B. I. Ma, M. Mendez, and K. Syndulko, "Multiple sclerosis de novo CNS IgG synthesis: effect of ACTH and corticosteroids," Neurology, vol. 30, no. 11, pp. 1155-1162, 1980.

[85] P. S. Rommer, F. Kamin, A. Petzold et al., "Effects of repeated intrathecal triamcinolone-acetonide application on cerebrospinal fluid biomarkers of axonal damage and glial activity in multiple sclerosis patients," Molecular Diagnosis \& Therapy, vol. 18, no. 6, pp. 631-637, 2014.

[86] W. W. Tourtellotte, K. Murthy, D. Brandes et al., "Schemes to eradicate the multiple sclerosis central nervous system immune reaction," Neurology, vol. 26, no. 6, part 2, pp. 59-61, 1976.

[87] J. R. Rinker II, K. Trinkaus, and A. H. Cross, "Elevated CSF free kappa light chains correlate with disability prognosis in multiple sclerosis," Neurology, vol. 67, no. 7, pp. 1288-1290, 2006.

[88] R. A. Rudick, D. L. Cookfair, N. A. Simonian et al., "Cerebrospinal fluid abnormalities in a phase III trial of Avonex (IFNbeta-1a) for relapsing multiple sclerosis. The Multiple Sclerosis Collaborative Research Group," Journal of Neuroimmunology, vol. 93, no. 1-2, pp. 8-14, 1999.

[89] L. D. Wilkerson, R. P. Lisak, B. Zweiman, and D. H. Silberberg, "Antimyelin antibody in multiple sclerosis: no change during immunosuppression," Journal of Neurology Neurosurgery and Psychiatry, vol. 40, no. 9, pp. 872-875, 1977.

[90] D. Caputo, M. Zaffaroni, A. Ghezzi, and C. L. Cazzullo, "Azathioprine reduces intrathecal IgG synthesis in multiple sclerosis," Acta Neurologica Scandinavica, vol. 75, no. 2, pp. 8486, 1987.

[91] J. Miro, F. Aguayo, J. C. Garrido et al., "Intrathecal immunoglobulin synthesis in multiple sclerosis: effect of corticosteroids and azathioprine," European Neurology, vol. 32, no. 6, pp. 349-353, 1992.

[92] P. C. Dau, J. H. Petajan, K. P. Johnson, H. S. Panitch, and M. B. Bornstein, "Plasmapheresis in multiple sclerosis: preliminary findings," Neurology, vol. 30, no. 10, pp. 1023-1028, 1980.

[93] W. W. Tourtellotte, A. R. Potvin, M. Mendez et al., "Failure of intravenous and intrathecal cytarabine to modify central nervous system IgG synthesis in multiple sclerosis," Annals of Neurology, vol. 8, no. 4, pp. 402-408, 1980.

[94] W. W. H. Shih, R. W. Baumhefner, W. W. Tourtellotte, C. M. Haskell, E. L. Korn, and J. L. Fahey, "Difference in effect of single immunosuppressive agents (cyclophosphamide, CCNU, 5-FU) on peripheral blood immune cell parameters and central nervous system immunoglobulin synthesis rate in patients with multiple sclerosis," Clinical and Experimental Immunology, vol. 53, no. 1, pp. 122-132, 1983.

[95] S. A. Sadiq, E. V. Simon, and L. M. Puccio, "Intrathecal methotrexate treatment in multiple sclerosis," Journal of Neurology, vol. 257, no. 11, pp. 1806-1811, 2010.

[96] R. A. Nash, J. D. Bowen, P. A. McSweeney et al., "High-dose immunosuppressive therapy and autologous peripheral blood stem cell transplantation for severe multiple sclerosis," Blood, vol. 102, no. 7, pp. 2364-2372, 2003.

[97] A. Salmaggi, C. Milanese, M. Eoli, L. La Mantia, A. Nespolo, and A. Dufour, "Immunological monitoring and clinical evaluation in cyclophosphamide-treated progressive multiple sclerosis patients," International Journal of Neuroscience, vol. 76, no. 3-4, pp. 305-312, 1994.

[98] M. Wender, E. Tokarz, G. Michalowska, and A. Wajgt, “Therapeutic trials of multiple sclerosis and intrathecal IgG production," Italian Journal of Neurological Sciences, vol. 7, no. 2, pp. 205-208, 1986.

[99] O. Martínez-Maza, D. J. Moody, A. R. Rezal et al., “Increased spontaneous immunoglobulin secretion associated with cyclophosphamide-induced immune suppression," Journal of Clinical Immunology, vol. 7, no. 2, pp. 107-113, 1987.

[100] O. R. Hommes, F. Aerts, U. Bahr, and H. R. Schulten, "Cyclophosphamide levels in serum and spinal fluid of multiple sclerosis patients treated with immunosuppression," Journal of the Neurological Sciences, vol. 58, no. 2, pp. 297-303, 1983.

[101] J. Lee, T. G. Choi, J. Ha, and S. S. Kim, "Cyclosporine A suppresses immunoglobulin $\mathrm{G}$ biosynthesis via inhibition of cyclophilin B in murine hybridomas and B cells," International Immunopharmacology, vol. 12, no. 1, pp. 42-49, 2012.

[102] B. N. McLean, P. Rudge, and E. J. Thompson, "Cyclosporin A curtails the progression of free light chain synthesis in the CSF of patients with multiple sclerosis," Journal of Neurology Neurosurgery and Psychiatry, vol. 52, no. 4, pp. 529-531, 1989.

[103] P. Rudge, J. C. Koetsier, J. Mertin et al., "Randomised double blind controlled trial of cyclosporin in multiple sclerosis," Journal of Neurology Neurosurgery \& Psychiatry, vol. 52, no. 5, pp. 559-565, 1989.

[104] M. P. Pender, P. A. Csurhes, C. Smith et al., "Epstein-Barr virusspecific adoptive immunotherapy for progressive multiple sclerosis," Multiple Sclerosis, vol. 20, no. 11, pp. 1541-1544, 2014.

[105] M. Axelsson, N. Mattsson, C. Malmeström, H. Zetterberg, and J. Lycke, "The influence of disease duration, clinical course, and immunosuppressive therapy on the synthesis of intrathecal oligoclonal IgG bands in multiple sclerosis," Journal of Neuroimmunology, vol. 264, no. 1-2, pp. 100-105, 2013.

[106] E. Evdoshenko, A. Maslyanskiy, S. Lapin et al., "Dynamics of B-cell populations in CSF and blood in patients treated with a combination of rituximab and mitoxantrone," ISRN Neurology, vol. 2013, Article ID 748127, 8 pages, 2013.

[107] G. A. Hill-Cawthorne, T. Button, O. Tuohy et al., "Long term lymphocyte reconstitution after alemtuzumab treatment of multiple sclerosis," Journal of Neurology, Neurosurgery and Psychiatry, vol. 83, no. 3, pp. 298-304, 2012. 
[108] J. C. Sipe, J. S. Romine, J. A. Koziol, R. McMillan, J. Zyroff, and E. Beutler, "Cladribine in treatment of chronic progressive multiple sclerosis," The Lancet, vol. 344, no. 8914, pp. 9-13, 1994.

[109] R. Gold, G. Giovannoni, K. Selmaj et al., "Daclizumab high-yield process in relapsing-remitting multiple sclerosis (SELECT): a randomised, double-blind, placebo-controlled trial," The Lancet, vol. 381, no. 9884, pp. 2167-2175, 2013.

[110] B. Bielekova, N. Richert, M. L. Herman et al., "Intrathecal effects of daclizumab treatment of multiple sclerosis," Neurology, vol. 77, no. 21, pp. 1877-1886, 2011.

[111] J. S. A. Perry, S. Han, Q. Xu et al., "Inhibition of LTi cell development by CD25 blockade is associated with decreased intrathecal inflammation in multiple sclerosis," Science Translational Medicine, vol. 4, no. 145, Article ID 145ra106, 2012.

[112] M. C. Kowarik, H. L. Pellkofer, S. Cepok et al., "Differential effects of fingolimod (FTY720) on immune cells in the CSF and blood of patients with MS," Neurology, vol. 76, no. 14, pp. 12141221, 2011.

[113] T. Holmøy, A. Lossius, T. E. Gundersen et al., "Intrathecal levels of vitamin D and IgG in multiple sclerosis," Acta Neurologica Scandinavica, vol. 125, no. 6, pp. e28-e31, 2012.

[114] S. Chen, G. P. Sims, X. C. Xiao, Y. G. Yue, and P. E. Lipsky, "Modulatory effects of 1,25-dihydroxyvitamin $\mathrm{D}_{3}$ on human $\mathrm{B}$ cell differentiation," The Journal of Immunology, vol. 179, no. 3, pp. 1634-1647, 2007.

[115] L. Rolf, A. H. Muris, R. Hupperts, and J. Damoiseaux, "Vitamin D effects on B cell function in autoimmunity," Annals of the New York Academy of Sciences, vol. 1317, no. 1, pp. 84-91, 2014.

[116] M. Soilu-Hänninen, L. Airas, I. Mononen, A. Heikkilä, M. Viljanen, and A. Hänninen, "25-Hydroxyvitamin D levels in serum at the onset of multiple sclerosis," Multiple Sclerosis, vol. 11, no. 3, pp. 266-271, 2005.

[117] M. H. J. Vogt, J. T. Kate, R. J. M. Drent, C. H. Polman, and R. Hupperts, "Increased osteopontin plasma levels in multiple sclerosis patients correlate with bone-specific markers," Multiple Sclerosis, vol. 16, no. 4, pp. 443-449, 2010.

[118] H. Openshaw, B. T. Lund, A. Kashyap et al., "Peripheral blood stem cell transplantation in multiple sclerosis with busulfan and cyclophosphamide conditioning: report of toxicity and immunological monitoring," Biology of Blood and Marrow Transplantation, vol. 6, no. 5, pp. 563-575, 2000.

[119] A. S. Fassas, J. R. Passweg, A. Anagnostopoulos et al., "Hematopoietic stem cell transplantation for multiple sclerosis: a retrospective multicenter study," Journal of Neurology, vol. 249, no. 8, pp. 1088-1097, 2002.

[120] J. P. A. Samijn, P. A. W. te Boekhorst, T. Mondria et al., "Intense $\mathrm{T}$ cell depletion followed by autologous bone marrow transplantation for severe multiple sclerosis," Journal of Neurology, Neurosurgery and Psychiatry, vol. 77, no. 1, pp. 46-50, 2006.

[121] J. D. Bowen, G. H. Kraft, A. Wundes et al., "Autologous hematopoietic cell transplantation following high-dose immunosuppressive therapy for advanced multiple sclerosis: long-term results," Bone Marrow Transplantation, vol. 47, no. 7, pp. 946-951, 2012.

[122] T. Mondria, C. H. J. Lamers, P. A. W. te Boekhorst, J. W. Gratama, and R. Q. Hintzen, "Bone-marrow transplantation fails to halt intrathecal lymphocyte activation in multiple sclerosis," Journal of Neurology, Neurosurgery and Psychiatry, vol. 79, no. 9, pp. 1013-1015, 2008.

[123] M. Inglese, G. L. Mancardi, E. Pagani et al., "Brain tissue loss occurs after suppression of enhancement in patients with multiple sclerosis treated with autologous haematopoietic stem cell transplantation," Journal of Neurology, Neurosurgery and Psychiatry, vol. 75, no. 4, pp. 643-644, 2004.

[124] J.-Q. Lu, J. T. Joseph, R. A. Nash et al., "Neuroinflammation and demyelination in multiple sclerosis after allogeneic hematopoietic stem cell transplantation," Archives of Neurology, vol. 67, no. 6, pp. 716-722, 2010.

[125] H. M. Bramlett, S. Kraydieh, E. J. Green, and W. D. Dietrich, "Temporal and regional patterns of axonal damage following traumatic brain injury: a beta-amyloid precursor protein immunocytochemical study in rats," Journal of Neuropathology and Experimental Neurology, vol. 56, no. 10, pp. 1132-1141, 1997.

[126] I. Metz, C. F. Lucchinetti, H. Openshaw et al., "Autologous haematopoietic stem cell transplantation fails to stop demyelination and neurodegeneration in multiple sclerosis," Brain, vol. 130, no. 5, pp. 1254-1262, 2007.

[127] J.-Q. Lu, J. Storek, L. Metz et al., "Continued disease activity in a patient with multiple sclerosis after allogeneic hematopoietic cell transplantation," Archives of Neurology, vol. 66, no. 1, pp. 116-120, 2009.

[128] A. Saiz, E. Carreras, J. Berenguer et al., "MRI and CSF oligoclonal bands after autologous hematopoietic stem cell transplantation in MS," Neurology, vol. 56, no. 8, pp. 1084-1089, 2001.

[129] P. Braendstrup, A. R. Langkilde, K. Schreiber, M. Ravnborg, F. Sellebjerg, and L. Vindeløv, "Progression and CSF inflammation after eradication of oligoclonal bands in an MS patient treated with allogeneic hematopoietic cell transplantation for follicular lymphoma," Case Reports in Neurology, vol. 4, no. 2, pp. 101-106, 2012.

[130] H.-C. von Büdingen, A. Bar-Or, and S. S. Zamvil, "B cells in multiple sclerosis: connecting the dots," Current Opinion in Immunology, vol. 23, no. 6, pp. 713-720, 2011.

[131] J. Storek, Z. Zhao, E. Lin et al., "Recovery from and consequences of severe iatrogenic lymphopenia (induced to treat autoimmune diseases)," Clinical Immunology, vol. 113, no. 3, pp. 285-298, 2004.

[132] O. Stüve, C. M. Marra, K. R. Jerome et al., "Immune surveillance in multiple sclerosis patients treated with natalizumab," Annals of Neurology, vol. 59, no. 5, pp. 743-747, 2006.

[133] M. del Pilar Martin, P. D. Cravens, R. Winger et al., "Decrease in the numbers of dendritic cells and $\mathrm{CD} 4^{+} \mathrm{T}$ cells in cerebral perivascular spaces due to natalizumab," Archives of Neurology, vol. 65, no. 12, pp. 1596-1603, 2008.

[134] F. von Glehn, A. S. Farias, A. C. P. de Oliveira et al., "Disappearance of cerebrospinal fluid oligoclonal bands after natalizumab treatment of multiple sclerosis patients," Multiple Sclerosis, vol. 18, no. 7, pp. 1038-1041, 2012.

[135] A. Harrer, H. Tumani, S. Niendorf et al., "Cerebrospinal fluid parameters of B cell-related activity in patients with active disease during natalizumab therapy," Multiple Sclerosis, vol. 19, no. 9, pp. 1209-1212, 2013.

[136] R. Mancuso, D. Franciotta, M. Rovaris et al., "Effects of natalizumab on oligoclonal bands in the cerebrospinal fluid of multiple sclerosis patients: a longitudinal study," Multiple Sclerosis, vol. 20, no. 14, pp. 1900-1903, 2014.

[137] J. R. Christensen, R. Ratzer, L. Bornsen et al., "Natalizumab in progressive MS: results of an open-label, phase 2A, proof-ofconcept trial," Neurology, vol. 82, no. 17, pp. 1499-1507, 2014.

[138] C. Warnke, M. Stettner, V. Lehmensiek et al., "Natalizumab exerts a suppressive effect on surrogates of B cell function in blood and CSF," Multiple Sclerosis Journal. In press. 
[139] M. Niino, C. Bodner, M.-L. Simard et al., "Natalizumab effects on immune cell responses in multiple sclerosis," Annals of Neurology, vol. 59, no. 5, pp. 748-754, 2006.

[140] M. Krumbholz, I. Meinl, T. Kümpfel, R. Hohlfeld, and E. Meinl, "Natalizumab disproportionately increases circulating pre-B and B cells in multiple sclerosis," Neurology, vol. 71, no. 17, pp. 1350-1354, 2008.

[141] R. Planas, I. Jelčić, S. Schippling, R. Martin, and M. Sospedra, "Natalizumab treatment perturbs memory- and marginal zonelike B-cell homing in secondary lymphoid organs in multiple sclerosis," European Journal of Immunology, vol. 42, no. 3, pp. 790-798, 2012.

[142] C. de Andrés, R. Teijeiro, B. Alonso et al., "Long-term decrease in VLA-4 expression and functional impairment of dendritic cells during natalizumab therapy in patients with multiple sclerosis," PLoS ONE, vol. 7, no. 4, Article ID e34103, 2012.

[143] R. C. Selter, V. Biberacher, V. Grummel et al., "Natalizumab treatment decreases serum IgM and IgG levels in multiple sclerosis patients," Multiple Sclerosis, vol. 19, no. 11, pp. 14541461, 2013.

[144] N. L. Monson, P. D. Cravens, E. M. Frohman, K. Hawker, and M. K. Racke, "Effect of rituximab on the peripheral blood and cerebrospinal fluid B cells in patients with primary progressive multiple sclerosis," Archives of Neurology, vol. 62, no. 2, pp. 258264, 2005.

[145] O. Stüve, S. Cepok, B. Elias et al., "Clinical stabilization and effective B-lymphocyte depletion in the cerebrospinal fluid and peripheral blood of a patient with fulminant relapsingremitting multiple sclerosis," Archives of Neurology, vol. 62, no. 10, pp. 1620-1623, 2005.

[146] H. F. Petereit, W. Moeller-Hartmann, D. Reske, and A. Rubbert, "Rituximab in a patient with multiple sclerosis-effect on B cells, plasma cells and intrathecal IgG synthesis," Acta Neurologica Scandinavica, vol. 117, no. 6, pp. 399-403, 2008.

[147] L. Piccio, R. T. Naismith, K. Trinkaus et al., "Changes in B- and T-lymphocyte and chemokine levels with rituximab treatment in multiple sclerosis," Archives of Neurology, vol. 67, no. 6, pp. 707-714, 2010.

[148] K. Hawker, P. O'Connor, M. S. Freedman et al., "Rituximab in patients with primary progressive multiple sclerosis: results of a randomized double-blind placebo-controlled multicenter trial," Annals of Neurology, vol. 66, no. 4, pp. 460-471, 2009.

[149] J. L. Rubenstein, D. Combs, J. Rosenberg et al., "Rituximab therapy for CNS lymphomas: targeting the leptomeningeal compartment," Blood, vol. 101, no. 2, pp. 466-468, 2003.

[150] A. Harjunpää, T. Wiklund, J. Collan et al., "Complement activation in circulation and central nervous system after rituximab (anti-CD20) treatment of B-cell lymphoma," Leukemia and Lymphoma, vol. 42, no. 4, pp. 731-738, 2001.

[151] S. Rossi, C. Motta, V. Studer et al., "Tumor necrosis factor is elevated in progressive multiple sclerosis and causes excitotoxic neurodegeneration," Multiple Sclerosis, vol. 20, no. 3, pp. 304312, 2014.

[152] V. Studer, S. Rossi, C. Motta, F. Buttari, and D. Centonze, "Peripheral B cell depletion and central proinflammatory cytokine reduction following repeated intrathecal administration of rituximab in progressive multiple sclerosis," Journal of Neuroimmunology, vol. 276, no. 1-2, pp. 229-231, 2014.

[153] W. W. Tourtellotte and B. I. Ma, "Multiple sclerosis: the bloodbrain-barrier and the measurement of de novo central nervous system IgG synthesis," Neurology, vol. 28, no. 9, part 2, pp. 7683, 1978.
[154] O. Winter, C. Dame, F. Jundt, and F. Hiepe, "Pathogenic longlived plasma cells and their survival niches in autoimmunity, malignancy, and allergy," Journal of Immunology, vol. 189, no. 11, pp. 5105-5111, 2012.

[155] V. T. Chu and C. Berek, “The establishment of the plasma cell survival niche in the bone marrow," Immunological Reviews, vol. 251, no. 1, pp. 177-188, 2013. 


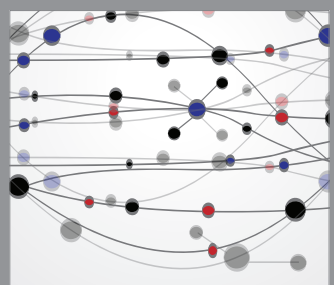

The Scientific World Journal
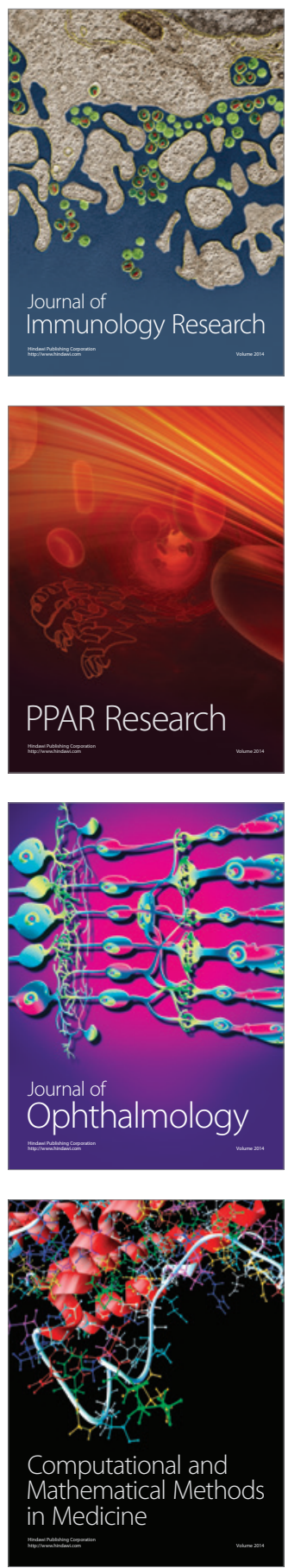

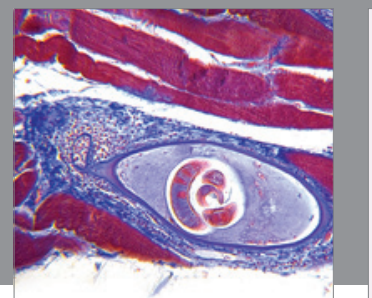

Gastroenterology

Research and Practice
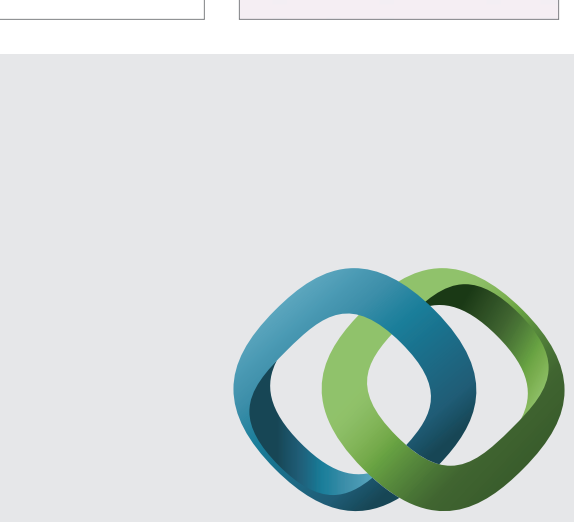

\section{Hindawi}

Submit your manuscripts at

http://www.hindawi.com
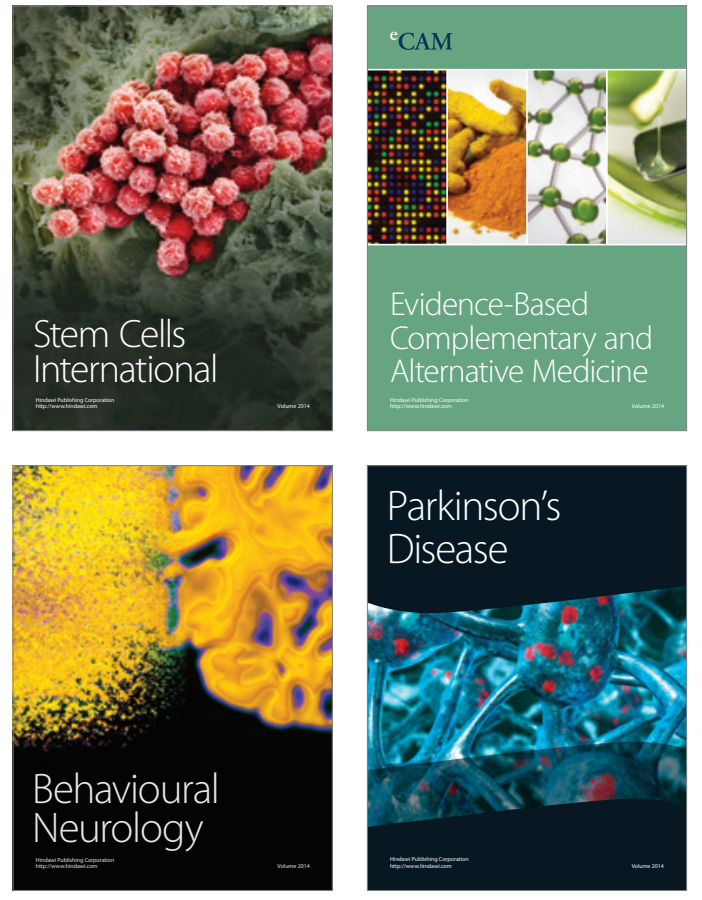
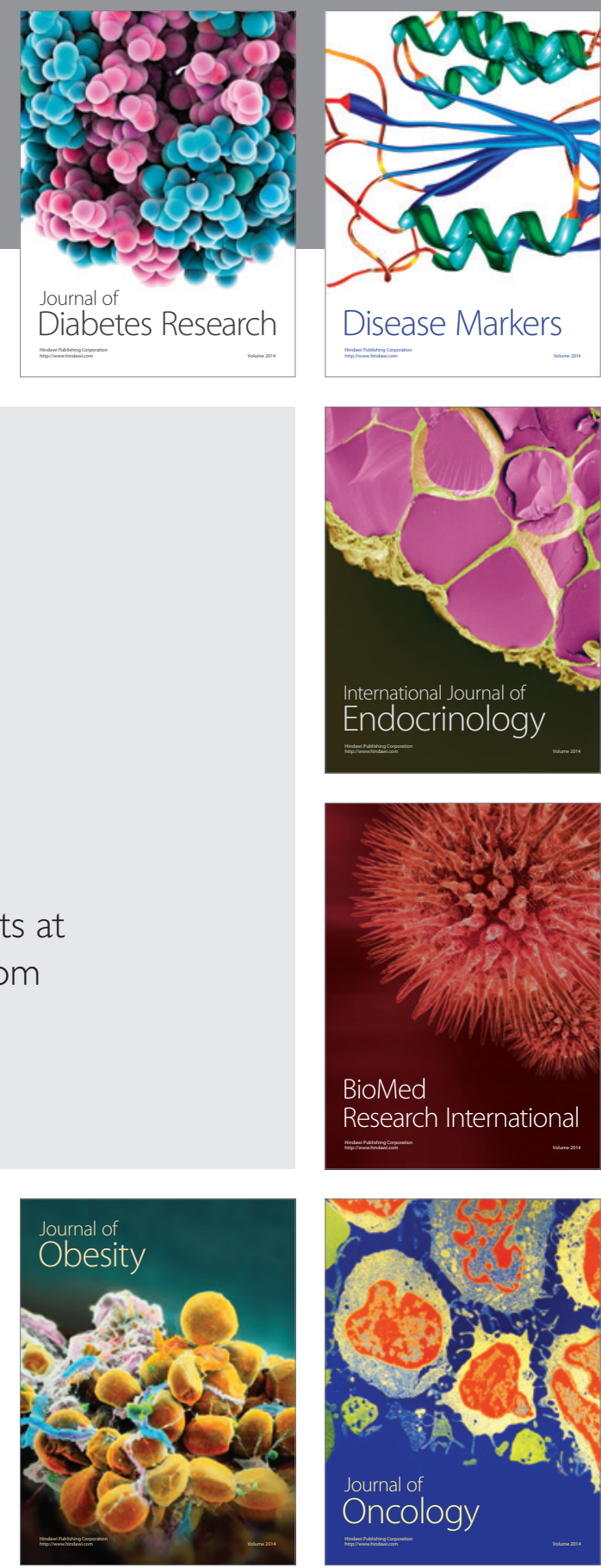

Disease Markers
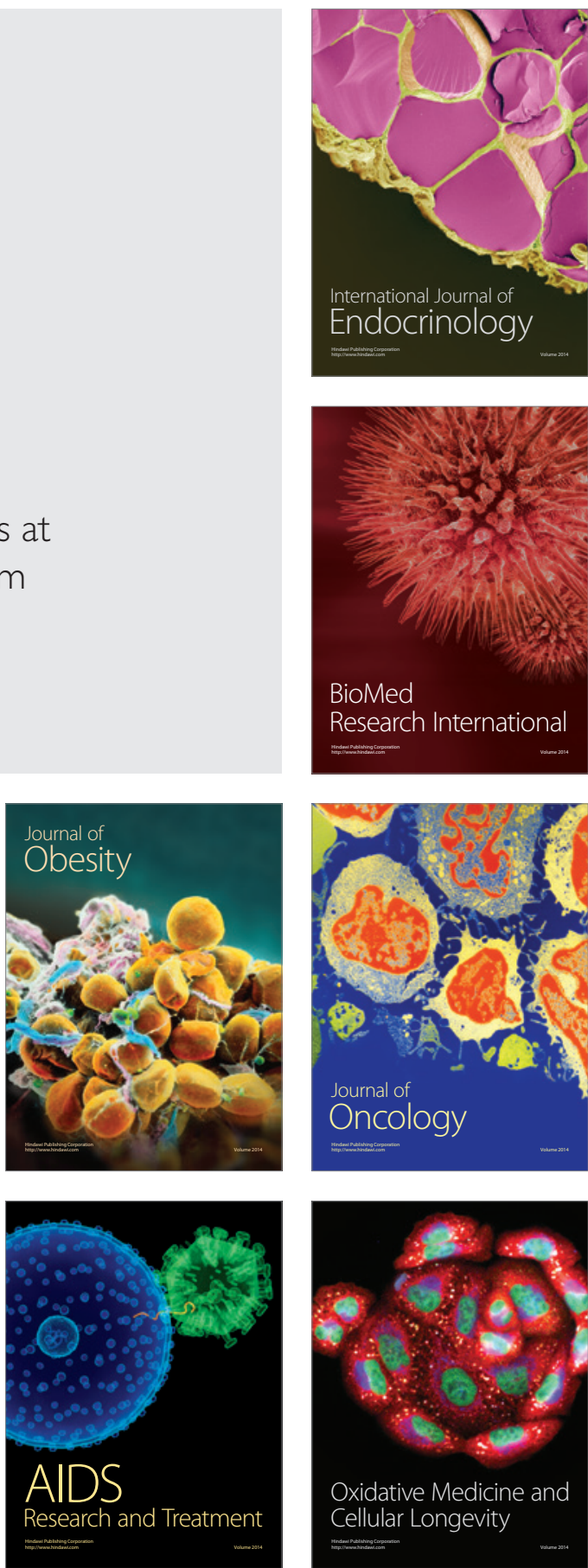